\title{
Characterization of a Twin-Entry Radial Turbine under Pulsatile Flow Condition
}

\author{
Mahfoudh Cerdoun ${ }^{1}$ and Adel Ghenaiet ${ }^{2}$ \\ ${ }^{1}$ Laboratory of Thermal Power Systems, Applied Mechanics, École Militaire Polytechnique, BP 17, Bordj-el-Bahri, 16046 Algiers, Algeria \\ ${ }^{2}$ Laboratory of Energetics and Conversion Systems, Faculty of Mechanical Engineering, University of Sciences and \\ Technology Houari Boumediene, BP 32, El-Alia, Bab Ezzouar, 16111 Algiers, Algeria
}

Correspondence should be addressed to Adel Ghenaiet; ag1964@yahoo.com

Received 19 December 2015; Revised 7 April 2016; Accepted 14 April 2016

Academic Editor: Funazaki Ken-ichi

Copyright (C) 2016 M. Cerdoun and A. Ghenaiet. This is an open access article distributed under the Creative Commons Attribution License, which permits unrestricted use, distribution, and reproduction in any medium, provided the original work is properly cited.

In automotive applications radial gas turbines are commonly fitted with a twin-entry volute connected to a divided exhaust manifold, ensuring a better scavenge process owing to less interference between engines' cylinders. This paper is concerned with the study of the unsteady performances related to the pulsating flows of a twin-entry radial turbine in engine-like conditions and the hysteresis-like behaviour during the pulses period. The results show that the aerodynamic performances deviate noticeably from the steady state and depend mainly on the time shifting between the actual output power and the isentropic power, which is distantly related to the apparent length. The maximum of efficiency and output shaft power are accompanied by low entropy generation through the shroud entry side, and their instantaneous behaviours tend to follow mainly the inlet total pressure curve. As revealed a billow is created by the interaction between the main flow and the infiltrated flow, affecting the flow incidence at rotor entry and producing high losses.

\section{Introduction}

In standard turbochargers, radial turbines are able to reach high expansion ratios in a short time by using the maximum energy of the gas flow pulses to raise the air density to internal combustion engines (ICE). However, at a low engine speed, the exhaust gas flow is small and the boost pressure is low. By using a twin-entry radial inflow turbine there is a better recovery of energy inducted alternatively and intermittently into the hub and shroud entries of the volute, and subsequently the dynamic pressure of exhaust gas flow pulses is used effectively. Romagnoli et al. [1] compared between the steady performances of two types of turbines, double-entry and twin-entry, and showed that, in the case of a twin-entry turbine, the interaction between entries is significant and causes the flow capacity to be larger than that which would be obtained by halving the mass flow in full admission, in contrast to a double-entry turbine. Pischinger and Wunsche [2] studied the interaction between the inlet gas flows from comparable double-entry and twin-entry volutes under steady conditions. At full admission, both of them produced a better efficiency, but at partial admission the efficiency of the twin-entry volute was significantly better, whereas at unequal inlet conditions there is a significant effect on the apparent flow characteristics and the turbine performance. Also, the performance of a twin-entry turbine was measured by Dale and Watson [3] over a wide range of partial admission conditions. As a result, the best efficiency is not under the full admission but occurs when the mass flow of the shroud-side entry is more than the hub-side entry. Steady and unsteady flow performances of an asymmetric twin-entry turbine of an automotive turbocharger were measured by Capobianco and Gambarotta [4] in both full admission and partial admission to highlight the interaction between the two entries and to show the effect of each entry of the volute on the full and partial admission conditions. Romagnoli et al. [5] modified a nozzleless turbine into a variable geometry single-entry turbine and a twin-entry turbine which were tested. The steady state experiment revealed that at a vane angle of 70 deg the effect of divider is not significant in 
terms of efficiency; however a significant depreciation in efficiency was measured for a vane angle between 50 deg and $40 \mathrm{deg}$. Further, an optimum vane angle of $60 \mathrm{deg}$ was found for the twin-entry turbine. Based on unsteady experiments for the same modified turbine, Rajoo et al. [6] showed that the swallowing capacity of a twin-entry turbine, in inphase testing during full admission, was inconsistent between the two entries. Contrarily, during out-phase testing the swallowing capacity of both entries was found to be similar. The performance of an asymmetric twin-entry radial turbine was investigated analytically and experimentally by Hajilouy et al. [7] under steady state conditions, considering the full and partial admission. As results, for a very high ratio of mass flow rates between the shroud-side and hub-side, the efficiency is lower than that of the full admission.

Engine exhaust pulse flows can significantly affect the turbine performance of a turbocharger; hence it is necessary to consider the pulse flow effects in the turbine design and performance analysis. Many researchers were interested in the effects of pulsatile flows, such as Serrano et al. [8] who determined the performance of a small radial inflow turbine working under pulsatile flows and compared with the one measured from cold pulsating flows. Iwasaki et al. [9] performed steady and unsteady flow measurements on a twin-entry turbine coupled to a 6-cylinder medium duty diesel engine. They found that for a fixed turbocharger speed and expansion ratio the unsteady flow mass flow parameter was lower than that corresponding to the steady flow value over the tested operating range. Ehrlich [10] performed measurements in an engine test cell on a turbocharged medium speed 6-cylinder diesel engine with the focus on understanding the process of energy transport from the cylinders to the twin-entry turbine admission. They measured the instantaneous total and static pressures by using inhouse constructed probes connected to a high frequency dynamic pressure transducer. The results indicated that the transport mechanism of the gas pulses energy in the exhaust manifold must be modelled as both convective and acoustic propagation of a wave. Dale and Watson [3] measured the shaft power of a twin-entry turbine working in pulsatile flow and concluded that the efficiency varies with admission, and the lowest efficiency occurs when the flow enters only one of the two entries. Rajoo and Martinez-Botas [11] discussed the performance of a twin-entry variable geometry turbine tested under the pulsating flow conditions and concluded that the swallowing capacity during the full admission was inconsistent, and the shroud entry was more pressurized compared to the hub entry. Owing to many difficulties in measuring the unsteady performance of radial turbines and the necessity of fully understanding their internal flows, CFD studies are used to surmount the lack of data. Lam et al. [12] performed a numerical study of the pulsatile flow in a radial nozzled turbine based on the frozen rotor interface. The results show that the instantaneous performance varies slightly from the nonpulsatile flow conditions, thus allowing concluding that the rotor can be treated as a quasi-steady domain while the volute must be treated as a non-quasisteady flow device. Also, Palfreyman and Martinez-Botas [13] investigated the pulsatile flow in a medium sized mixed flow nozzleless turbine based on URANS computations, RNG- $k \epsilon$ turbulence model, and sliding mesh model (SMM) at volute-rotor interface. They concluded that the agreement with the flow field measurements for both the cycle averaged and instantaneous data was reasonable and the sliding mesh model showed better results than the moving reference frame as adopted by Lam et al. [12]. Hellstrom and Fuchs [14-16] carried out numerical flow analyses of a nozzleless turbine in the case of pulsatile inlet conditions, considering large eddy simulations (LES) implemented in the commercial code STAR-CD. Their first report [14] treated two cases of an ICE rotational speed (1500 rpm, $3000 \mathrm{rpm})$ and concluded that the entry of rotor into the flow angle varies from $-67 \mathrm{deg}$ to $-25 \mathrm{deg}$ for the second speed which was more favourable than the first speed where the flow angle is from $-85 \mathrm{deg}$ to $60 \mathrm{deg}$, resulting in a drop of the peak shaft power about $4 \%$. The results of Palfreyman and Martinez-Botas [13] showed that the incidence angle varied from $-92 \mathrm{deg}$ to $60 \mathrm{deg}$.

Recently, Padzillah et al. [17] based on a full 3D CFD model studied the influence of the speed and the frequency of pulses on a mixed radial turbine. The temporal and spatial resolutions of the flow incidence suggested that the circumferential variation is less than $7 \%$ compared to its variation in time as the pulses progress. They found that there is no direct instantaneous relationship between the pulsating pressure and the turbine efficiency. The major difficulty in deriving the turbine performance is the shifting time between the isentropic conditions upstream of the turbine and the actual output work. Furthermore, the expansion process is highly unsteady as it responds to the exhaust manifolds of an ICE, and this is why its design and adaptation are a very difficult task owing to its operation in off-design conditions. There are still debates on the effective method of defining the efficiency of a turbine under the unsteady flow conditions due to the phase shifting, so a question arises: how can the time lag be evaluated? To answer this question, two parameters should be determined such as the transport mechanism speed of pressure wave and the apparent length which represents the average distance travelled by the wave from a measurement plan to a supposed position at the rotor entry. Three approaches have been adopted by researchers in order to estimate the time lag. The first approach, as proposed by Dale and Watson [3], is based on the sonic travel speed, arguing that the pressure waves propagate at this speed. Karamanis et al. [18] measured the static pressure development from the inlet measuring plane to the rotor entry at various locations upstream and downstream of the tongue and concluded that the only appropriate time to shift the signal is given by the sonic travel time; such an approach was adopted by many workers. The second approach suggests that the bulk of the flow transmission is more important than the pressure wave transmission, which was first proposed by Winterbone et al. [19] and followed by other workers. The third approach suggests that the transport mechanism must be modelled as both convective and acoustic propagation [10]. Recently, Szymko et al. [20] showed that the sum of sonic velocity and bulk flow velocity can lead to better results. Many researchers took the apparent length as the path length between the centres of volute sections from 
the measurement plan to a point at 180 deg removed from the tongue. Until now, there is yet no agreement about the approaches related to the pulses transport mechanism in order to characterize the unsteady turbine performance. However, the unsteady flow field measurements in twin-entry turbines are rare due to great demands on the measurement techniques, especially concerning the pulsating behaviour of flows and the high fluctuations of the total inlet temperature with the high rotational speed. The reasonable agreement between experiment and theory found by researches such as in $[13,21]$ may constitute a good support to a numerical study. Moreover, the efforts in characterizing the small radial turbines under the pulsatile flow conditions are hampered by some difficulties in the unsteady measurements. Often, the inlet pressure is measured as a time-varying quantity, but the total temperature, the mass flow rate, and the power are measured as time-mean quantities. In his survey, Baines [22] quoted very few facilities to investigate the pulsatile flows, and this is why the unsteady flow analyses based on CFD tools become useful.

The present paper is a contribution to predict the aerodynamic performance of a twin-entry radial turbine under pulsating flow conditions. The simulations consist in solving the unsteady 3D flows by means of Ansys-CFX URANS solver, considering appropriate inlet and exit boundary conditions. The method of time lag is focused on throughout this work. Indeed, there are difficulties in studying the unsteady flows both numerically and experimentally, owing to time difference between the instantaneously measured isentropic conditions and the actual turbine conditions. Furthermore, it is certain that the unsteady value of the turbine efficiency is related to the phase shifting and hence might lead to unrealistic values as quoted by Rajoo and Martinez-Botas [23]. The accuracy in estimating the time shifting may be of great help for improving the engine models in order to predict the real response of a turbocharger versus the pulsatile flows and therefore possibilities of comparing between different unsteady radial turbines' performances.

\section{Computational Domain}

The studied twin-entry radial turbine has a rotor with 12 blades, having an inlet diameter of $96 \mathrm{~mm}$ and an outlet diameter of $86.3 \mathrm{~mm}$ and a shroud blade angle of $37 \mathrm{deg}$. The geometry was obtained by means of a measuring machine equipped with a contactless optical feeler. The beam of light moves over the mapped surfaces to reproduce the correct blade shape. The nonsymmetric twin-entry volute is divided into two domains: inlet domain and 3D spiral domain (Figure 1). The surfaces at the inlet horizontal domain remain fixed, but the angles between the two slots vary because this domain is twisted. Next, there is a spiral volute where the angle between two plans remains constant and only the dimensions of the sides vary according to the spiral shape.

The pressure boundary condition will result in the reflection of outgoing waves, and subsequently the interior domain contains spurious wave reflections. Indeed, the nonreflecting boundary conditions provide a special treatment to the domain boundaries to control these spurious wave

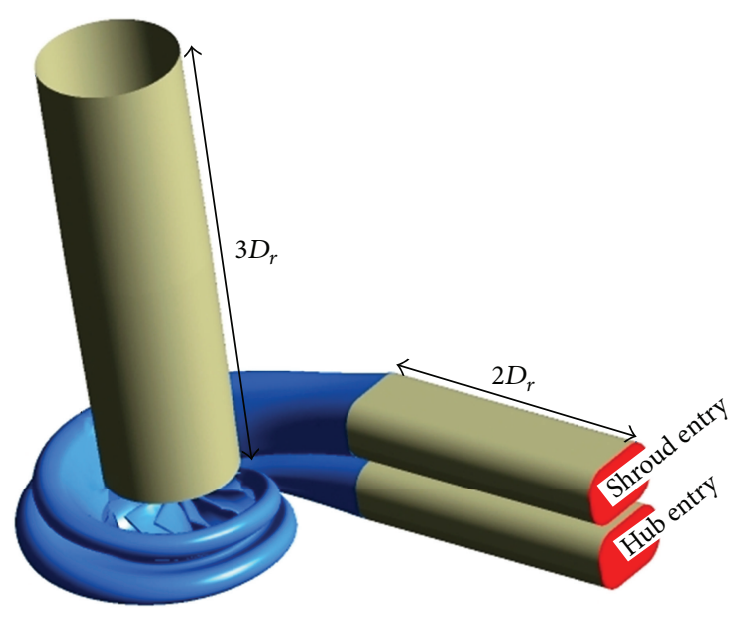

FIGURE 1: The twin-entry radial turbine.

reflections, but unfortunately these nonreflecting boundary conditions are not available for the pressure-based solver implemented in Ansys-CFX version 14.5; as a consequence, an induction pipe and a diffuser of length of $2 D_{r}$ and $3 D_{r}\left(D_{r}\right.$ represent inlet rotor (Figure 1)), respectively, were added to the inlet and outlet of this turbine, to avoid any interference produced by the boundaries.

The computational grids were created separately as shown by Figure 2(b). The rotor domain by means of TurboGrid adopted an $\mathrm{H}$-grid topology with an O-grid wrapped around the rotor blades in order to minimize the skew angles. Higher grid resolution was set on the blades surfaces, hub, and shroud with an expansion factor of 1.18 in order to model the near wall flows as accurately as possible. The tip gaps are about $0.11 \mathrm{~mm}$ and $0.205 \mathrm{~mm}$ (Figure 2(a)) and used twelve uniform cells to better capture the tip leakage flows. As a consequence, the total nodes used to mesh the rotor are 1599684 nodes. For the twin-entry volute a hexahedral mesh of 1063249 nodes was generated, in addition to 265006 nodes used for the exhaust. To study the grid size dependency the mesh distribution was changed around the blade surfaces and along the streamwise and spanwise directions, and five new grids were used to predict the turbine performance which seemed to stabilize above a grid size of 4.1 million. The flow was solved through the volute in a stationary frame and in a rotating frame for the rotor. In the present simulations, the $k \omega$-SST turbulence model with an automatic wall function was considered. The minimum and maximum values of $y^{+}$ on the surfaces of volute and rotor in the extreme inlet conditions were in between 0.2 and 68.5 , because it was difficult to have small values near the hub and tongue. When $y^{+}>2$, the solver automatically uses the wall function whereas the low Reynolds method is used for $y^{+} \leq 2$ such as the majority of blade surfaces.

\section{Pulsatile Flow Simulations}

The average values of pressure and temperature at inlet and outlet correspond to the real operating conditions obtained 


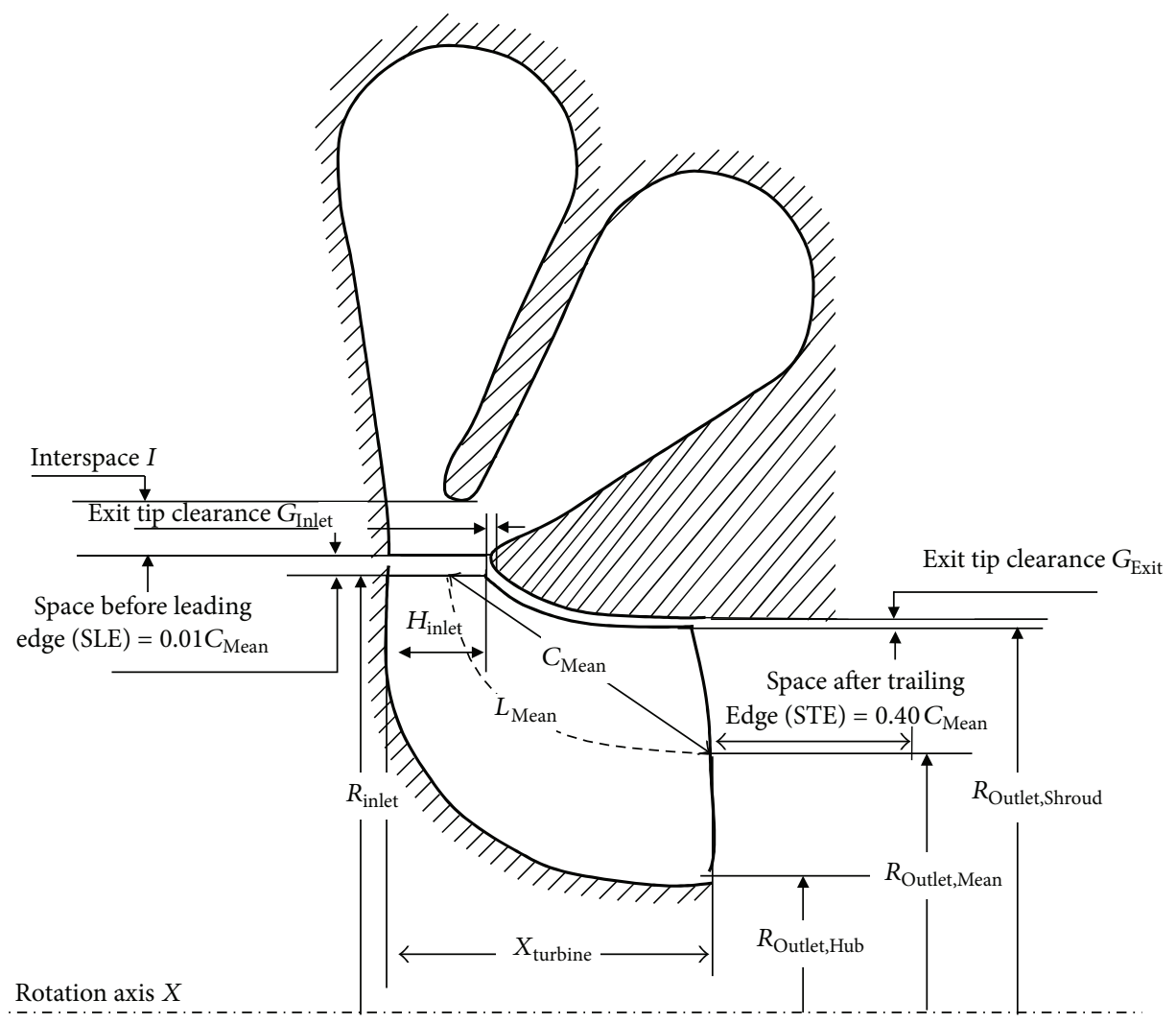

(a)
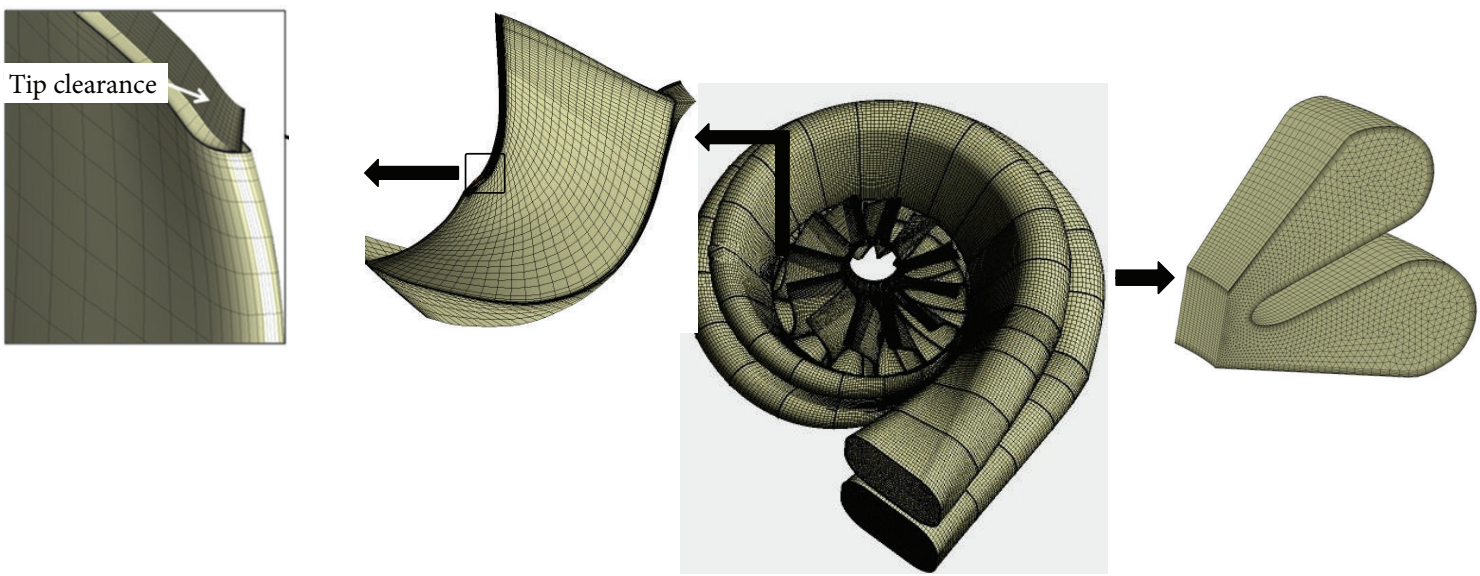

(b)

Figure 2: (a) Rotor and volute cross sections. (b) The generated meshes.

with a V12 diesel engine according to Ghenaiet [24]. On the other side, Ehrlich [10] performed extensive measurements of an in-line 6-cylinder medium speed diesel engine with a quite low output (5.9 litres, peak torque $569 \mathrm{Nm} @ 1600$ rpm), in order to analyze the on-engine turbine performance under pulsatile flows. The instantaneous total and static pressure at both the inlet and outlet of the twin-entry turbine were measured by constructed probes connected to a high frequency dynamic pressure transducer. The exhaust gases were ducted away from the exit of the turbocharger's turbine and discharged outside the test cell. The butterfly valves installed in the air intake and the gas exhaust set an inlet restriction and an exhaust backpressure. Ehrlich [10] used fine wire thermocouples to measure the significant temperature variation over the engine cycle.

In the present simulations, the pulsating behaviours of the total temperature $T_{t}^{\prime}$ and the total pressure $P_{t}^{\prime}$ identified by Ehrlich [10] were used and scaled (Figure 3) by the 


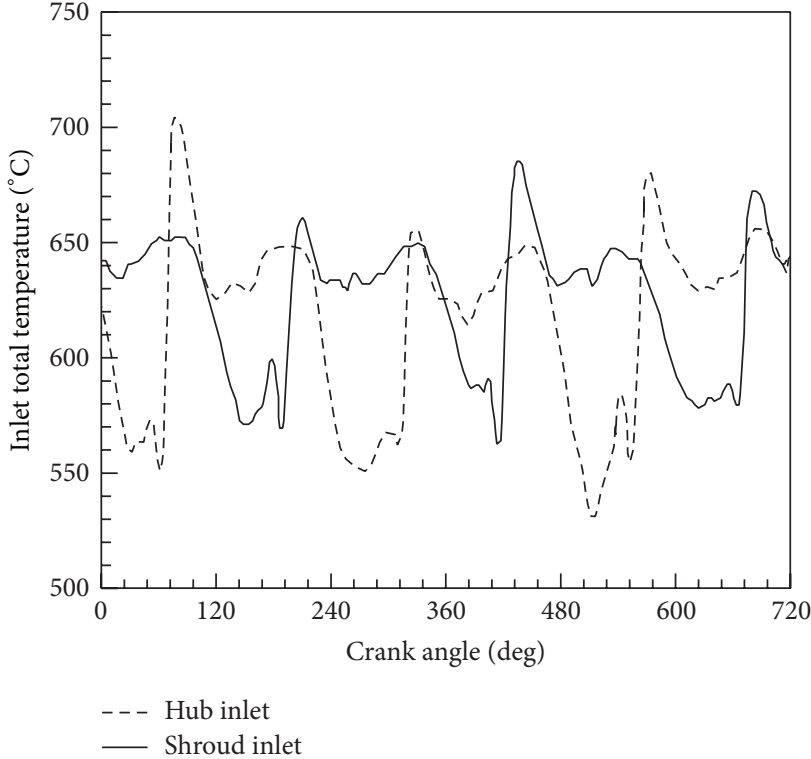

(a)

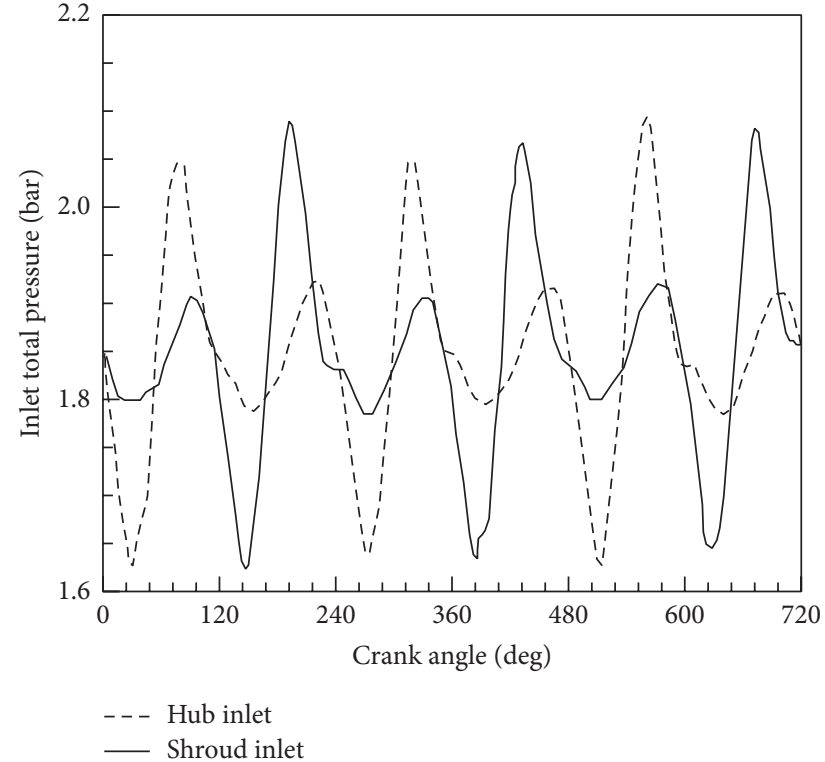

(b)

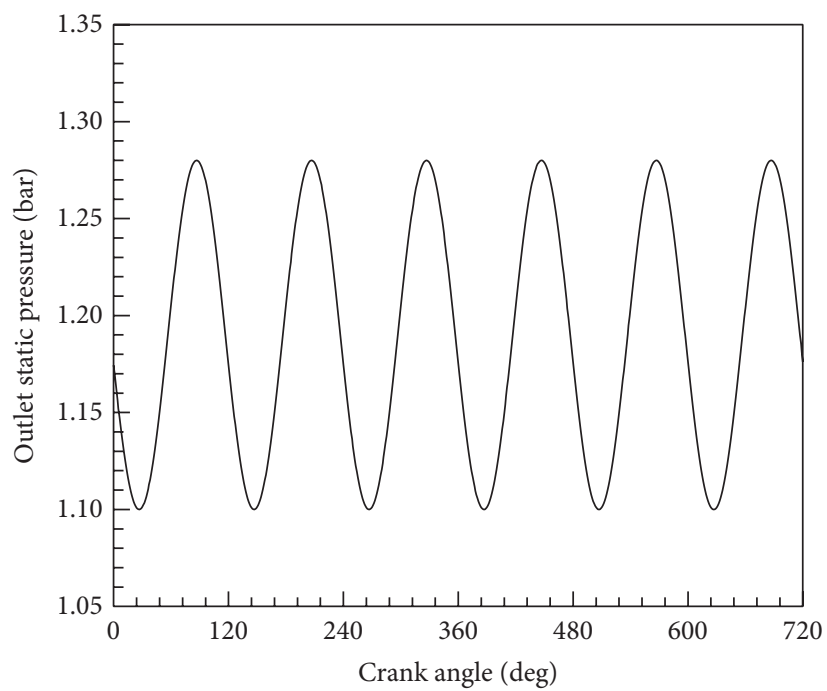

(c)

FIGURE 3: Boundary conditions, (a) inlet total pressure, (b) inlet total temperature, and (c) outlet static pressure.

measured average values of the total pressure and temperature (Ghenaiet [24]):

$$
\begin{aligned}
& P_{t}=P_{t}^{\prime}+\left(\overline{P_{t}}-\frac{1}{2 \pi} \int_{0}^{2 \pi} P_{t}^{\prime} d \theta\right) \\
& T_{t}=T_{t}^{\prime}+\left(\overline{T_{t}}-\frac{1}{2 \pi} \int_{0}^{2 \pi} T_{t}^{\prime} d \theta\right) .
\end{aligned}
$$

At the turbine exit, Ehrlich [10] showed that the static pressure perturbation is nearly sinusoidal and characterized by six pulses per engine cycle, and each pulse corresponds to one valve event in the six-cylinder engine, as mentioned above for the total temperature and pressure; the static pressure is chosen to verify the following equation:

$$
p=p^{\prime}+\left(\bar{p}-\frac{1}{2 \pi} \int_{0}^{2 \pi} p^{\prime} d \theta\right)
$$

The results of the simulations in terms of shaft power efficiency and expansion ratio will be presented in the next section. But first some parameters are introduced and defined. 
For each entry, the ratio of inlet mass flow to the inlet total mass flow (MFR) is given as follows:

$$
\begin{aligned}
\operatorname{MFR}_{s} & =\frac{\dot{m}_{s}}{\dot{m}_{s}+\dot{m}_{h}}, \\
\operatorname{MFR}_{h} & =\frac{\dot{m}_{h}}{\dot{m}_{s}+\dot{m}_{h}} .
\end{aligned}
$$

The reduced mass flow (RMF) parameter for the case of a twin-entry radial turbine is calculated by considering the contribution of the two entries, where each entry feeds half of the span of the entire circumference. Cumpsty and Horlock [25] suggested that the total temperature and pressure should be based on a clear view of the purpose for which the averaged values are intended. Therefore, the total temperature $T_{t}$ could be calculated as a mass weighed average value $\left(T_{t 0}=\mathrm{MFR}_{s}\right.$. $\left.T_{t s}+\mathrm{MFR}_{h} \cdot T_{t h}\right)$ since this gives the correct value of enthalpy flux, according to ideal gas assumptions. While for the total pressure $P_{t}$ it is noteworthy that as the magnitude of the total pressure is reduced the various average pressures become more nearly equal; thus a mass weighed average is also used for the total pressure $\left(P_{t 0}=\mathrm{MFR}_{s} \cdot P_{t s}+\mathrm{MFR}_{s} \cdot P_{t h}\right)$. The instantaneous reduced mass flow (RMF) parameter is given as follows:

$$
\mathrm{RMF}=\left(\dot{m}_{s}+\dot{m}_{h}\right) \frac{\sqrt{\mathrm{MFR}_{s} \cdot T_{t s}+\mathrm{MFR}_{h} \cdot T_{t h}}}{\left(\mathrm{MFR}_{s} \cdot P_{t s}+\mathrm{MFR}_{s} \cdot P_{t h}\right)}
$$

The total-to-static instantaneous expansion ratio for each entry and for the entire turbine is presented as follows:

$$
\begin{aligned}
\pi_{t s-s} & =\frac{P_{t s}}{P_{\text {out }}} \\
\pi_{t s-h} & =\frac{P_{t h}}{P_{\text {out }}} \\
\pi_{t s} & =\frac{P_{t 0}}{p_{\text {out }}} .
\end{aligned}
$$

In a turbocharger, the most important figure is the actual pressure of air delivered by the compressor driven by the turbine; thus the shaft power is very important and it is one of the global parameters to be evaluated:

$$
P=\vec{T}_{\text {Shaft }} \cdot \vec{\omega}_{\text {rotor }}
$$

where the shaft torque, $\vec{T}_{\text {Shaft }}$, is obtained by integrating the element forces due to pressure forces over the turbine rotor:

$$
\vec{T}_{\text {Shaft }}=\int_{s} \vec{r} \times(p \cdot \vec{n}) d s .
$$

The total-to-static efficiency can instead be calculated as the ratio between the utilized power and the maximum power variation of gases if expanding isentropically within a twin-entry radial turbine. The resulting expression for the instantaneous total-to-static efficiency is as follows:

$$
\eta_{t s}=\frac{\vec{T}_{\text {Shaft }} \cdot \vec{\omega}_{\text {rotor }}}{\dot{m}_{s} C p_{s} \cdot T_{t s}\left[1-\left(p_{\text {out }} / P_{t s}\right)^{(\gamma-1) / \gamma}\right]+\dot{m}_{h} C p_{h} \cdot T_{t h}\left[1-\left(p_{\text {out }} / P_{t h}\right)^{(\gamma-1) / \gamma}\right]}
$$

$\dot{m}_{s}$ and $\dot{m}_{h}$ are the mass flow within the shroud-side and hubside, respectively. $T_{t s}$ and $P_{t s}$ are the total gas temperature and pressure at the hub-side inlet, $T_{t h}$ and $P_{t h}$ are the total gas temperature and pressure at the hub-side inlet, and $p_{\text {out }}$ is the static pressure downstream of turbine. $C p_{s}$ and $C p_{h}$ are the specific heat of the gases at shroud-side and hubside, respectively, and $\gamma$ is the isentropic index. According to Hellstrom and Fuchs $[14,16]$ the above definition works well for nonpulsatile and for pulsatile flows at moderate frequencies.

\section{Unsteady Performance}

The results presented herein are aimed at better understanding the effects of pulsatile inlet conditions on the performance of a twin-entry radial turbine, especially the effect of phase shifting. Due to the huge total time required to simulate the overall four-stroke engine, a compromise between the accuracy and CPU time is required to make computations cost-effective. Thus, the total time is limited to a $600 \mathrm{deg}$ crank angle which corresponds to the complete two pulses incoming from the two entries and to 62.2 rounds of the turbine. The performance can be expressed in terms of the output shaft power, the efficiency, and the expansion ratio. Also an analysis of the flow structures between the shroudside and the hub-side of volute is provided at two planes situated at the volute/rotor interface.

4.1. Effect of the Pulsatile Flow. The important parameters for the current simulations are the total pressure loss factor $\zeta$ and the total-to-static isentropic efficiency $\eta_{t-s}$ which for the case of a twin-entry turbine are defined as follows:

$$
\begin{aligned}
\zeta= & \frac{\left(\mathrm{MFR}_{s} \cdot P_{t s}+\mathrm{MFR}_{s} \cdot P_{t h}\right)-P_{\mathrm{t} 1}}{\left(\mathrm{MFR}_{s} \cdot P_{t s}+\mathrm{MFR}_{s} \cdot P_{t h}\right)} \\
\eta_{t-s} & =\frac{\left(\mathrm{MFR}_{s} \cdot T_{t s}+\mathrm{MFR}_{h} \cdot T_{t h}\right)-T_{1}}{\left(\mathrm{MFR}_{s} \cdot T_{t s}+\mathrm{MFR}_{h} \cdot T_{t h}\right)-T_{1 s}},
\end{aligned}
$$

where $P_{t 1}, T_{1}$, and $T_{1 s}$ refer to the total pressure, static temperature, and isentropic static temperature at the volute exit, respectively. Since no work is done by the volute and the wall is assumed to be adiabatic, thus the total-to-static 


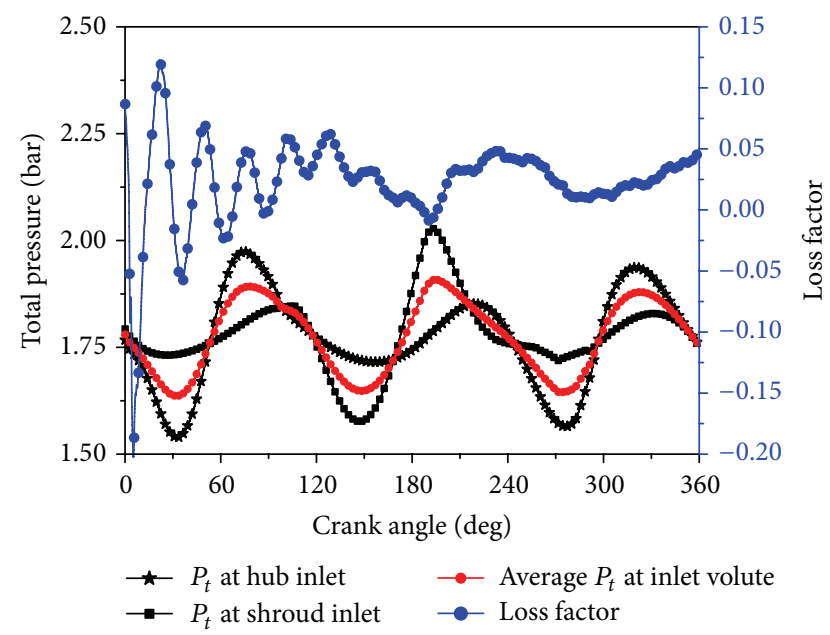

FigURE 4: Instantaneous total pressure and loss factor.

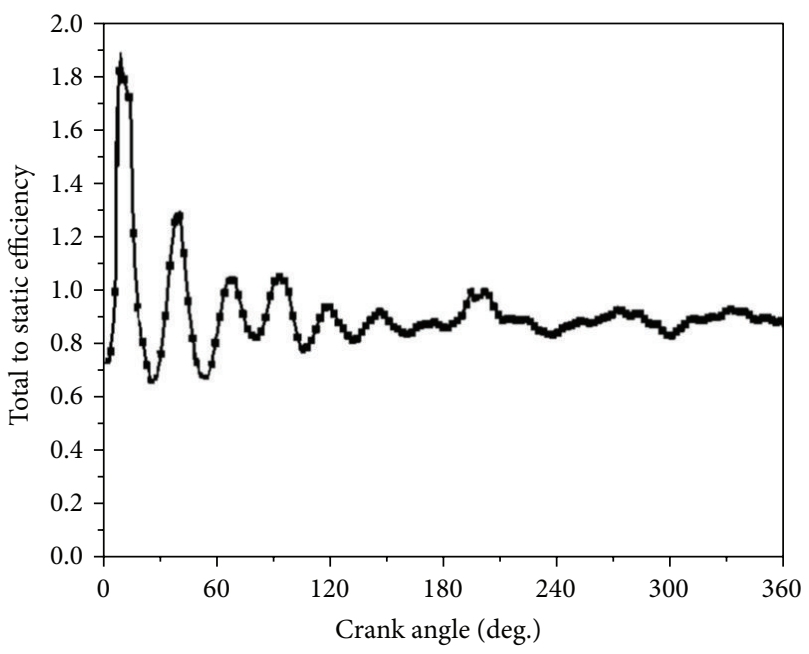

FIGURE 5: Unsteady total-to-static efficiency of the volute.

efficiency of the volute can be written as a function of pressure ratio as follows:

$$
\eta_{t-s}=\frac{1-\left(P_{1} / P_{t 1}\right)^{(\gamma-1) / \gamma}}{1-\left(P_{1} / P_{t 0}\right)^{(\gamma-1) / \gamma}} .
$$

Figures 4 and 5 show the response of the twin-entry volute to the pulsatile flow at inlet in terms of the total pressure loss factor and the total-to-static efficiency versus the crank angle. Except that at the beginning of simulations where the value of total pressure loss factor is negative or exceeds unity, the behaviour of loss factor is shown to be nearly in out-phase to the mean inlet total pressure. Similarly, the total-to-static isentropic efficiency of the twin-entry volute shows a strong behaviour during the first 60 deg of the crank angle and then tends to be in out-phase to the loss factor, since low losses lead to more efficiency.

The flow structures in the volute between shroud-side and hub-side are revealed (Figure 6) by the velocity vectors superimposed to the plot of the total pressure at two planes situated at the interface volute/rotor (radius $R 1=49 \mathrm{~mm}$ ) and at an interspace plane distant from the rotor entry about $1.5 \mathrm{~mm}$ (radius $R 2=51.5 \mathrm{~mm}$ ). Figure 6 depicts flow structures at three different instants: instant of a high total pressure at the shroud-side, instant of an equality of total pressure at the two entries, and an instant when the volute is highly fed through the hub-side entry. Before entering into the interspace represented by the space between the divider and the rotor inlet (about $6 \mathrm{~mm}$ in radial direction), the vectors are seen to be in the circumferential direction. However, since the flow attains the interspace area, the velocity vectors start deviating to the radial direction (plane of radius $R 2$ ). The flow entering from the shroud-side is characterized by an axial component provoked by the inclination of the two walls which constitute the shroud-side entry. This axial component seems to be more accentuated in the case of a high total pressure at the shroud-side, since the flow tends to migrate to the hub-side (Figure 6(a)). In the case of equal admission, the main flow within the shroud-side is shown to enter parallel to the divider, whereas the flow within the hub-side is parallel to the upper wall of volute (Figure 6(b)). At the instant when the volute is highly fed through the hub-side entry (Figure 6(c)), the flow entering the interspace from the hub-side tends to recover the shroud-side. The flow near the tongue is firstly affected by the previous infiltrated flow coming downstream of the tongue and feeding the rotor once more and secondly by the zone of flow mixture created upstream of the tongue between the two incoming flows. For the three instants, the velocity vectors near the tongue are shown to be inclined to the circumferential direction and then inclined largely to the radial direction. Also, the details of Figure 6 depict a rapid recovery of the flow as moving from the circumferential direction to the radial direction through the interspace of $6 \mathrm{~mm}$ for the three instants.

4.2. Instantaneous Isentropic and Actual Power. There is a certain distance existing between the locations of upstream and downstream planes used for calculating the turbine performance, which gives rise to a time lag between the phases for the respective quantities under pulsating flows. This time lag should be equal to the time taken by the pulse mechanism to travel between the two stations. In the case of a twin-entry radial turbine, the estimation of phase shift between the actual and the isentropic work seems to be more complicated as compared to a single-entry turbine because of the complex geometry and the interaction between the two entries. There are two major problems which are involved to find the time lag. The first is the flow velocity through the volute which varies considerably due to the progressive restriction of volute section from the inlet duct to the tongue, in addition to continuous variation of gas flow conditions at the inlet. The second is the distance separating the two measurements planes which cannot be clearly defined without a detailed evaluation of the path-lines, since the twinentry volute feeds the rotor circumferentially around $360 \mathrm{deg}$. Palfreyman and Martinez-Botas [13] and Arcoumanis et al. [26] showed that the time shift is mainly produced in the volute owing to its biggest characteristic length as compared to the rotor which may be studied as a quasi-steady pattern. 


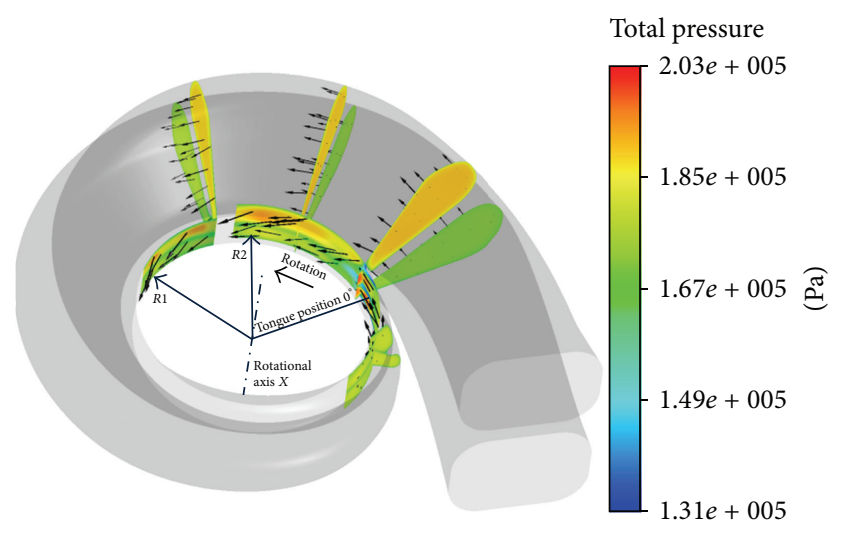

(a)

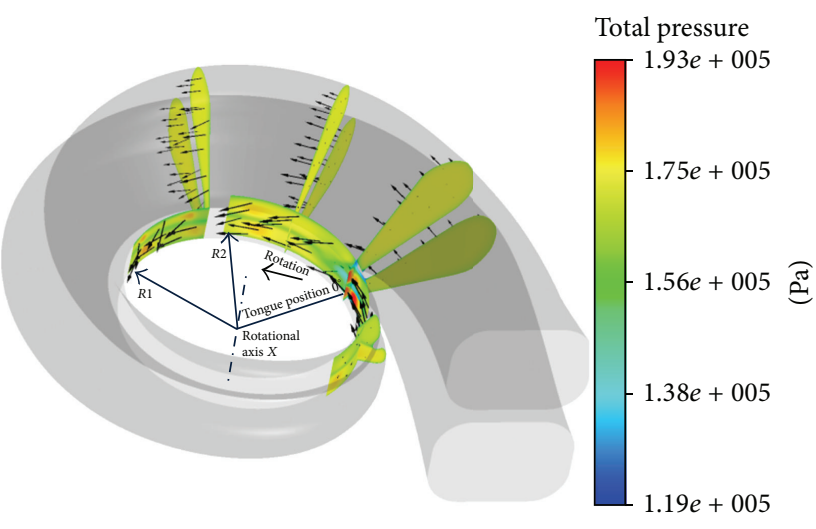

(b)

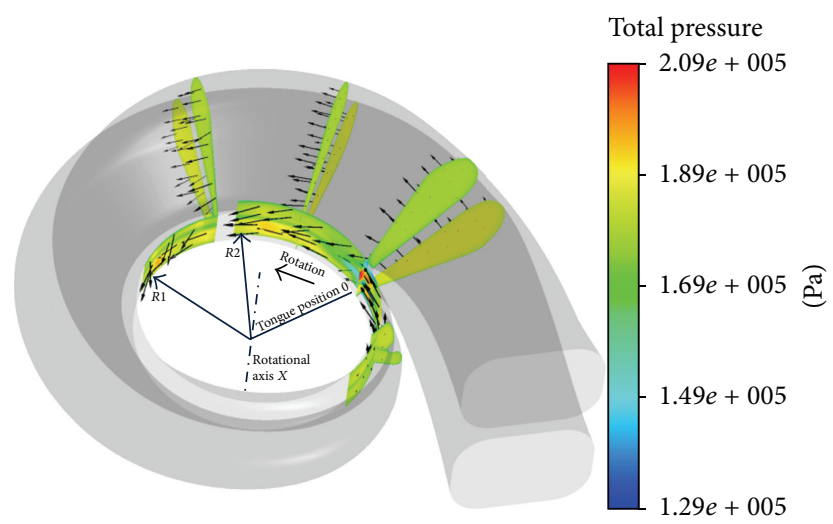

(c)

FIGURE 6: Velocity vectors over total pressure through the volute, at three different instants.
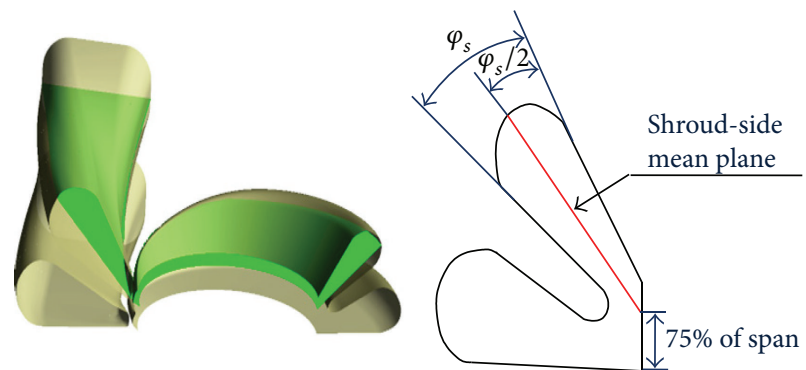

(a)
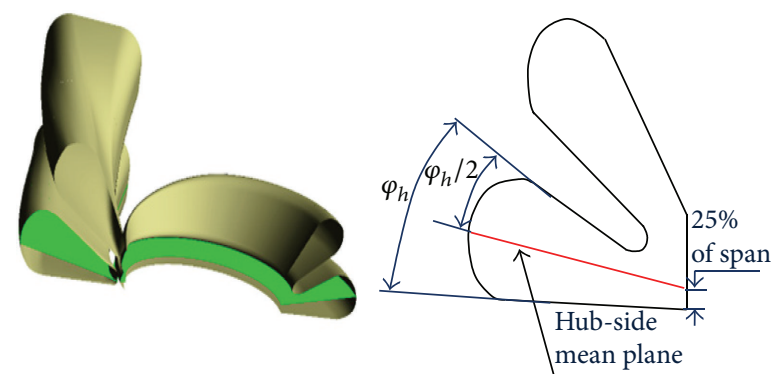

(b)

Figure 7: Mean planes of volute (a) shroud-side and (b) hub-side.

Therefore, in the present study the time shift is taken as the necessary time for the mechanism of pulse to travel from the inlet duct to the exit volute; hence the time shift $\tau$ is expressed as

$$
\tau=\frac{L}{V}
$$

where $L$ represents the apparent length and $V$ the velocity of pulse mechanism.

In order to estimate the velocity used to determine the time lag, two mean planes are plotted in the two entries as shown by Figure 7. For each entry and for each time step corresponding to $1.5 \mathrm{deg}$ of rotor rotation, the average area velocities (bulk flow velocity and sonic velocity and sum of them) were evaluated. By using the apparent length (assuming inlet rotor at $90 \mathrm{deg}, 180 \mathrm{deg}, 270 \mathrm{deg}$, or $360 \mathrm{deg}$ from the tongue), the mean time lag related to one time step can be calculated for the turbine, and the average of all the values of time lag could be taken as an approximation of the global time lag.

The results of the simulated actual power and the isentropic inlet power versus the crank angle are presented in Figure 8 . The unsteady isentropic power is presented as 


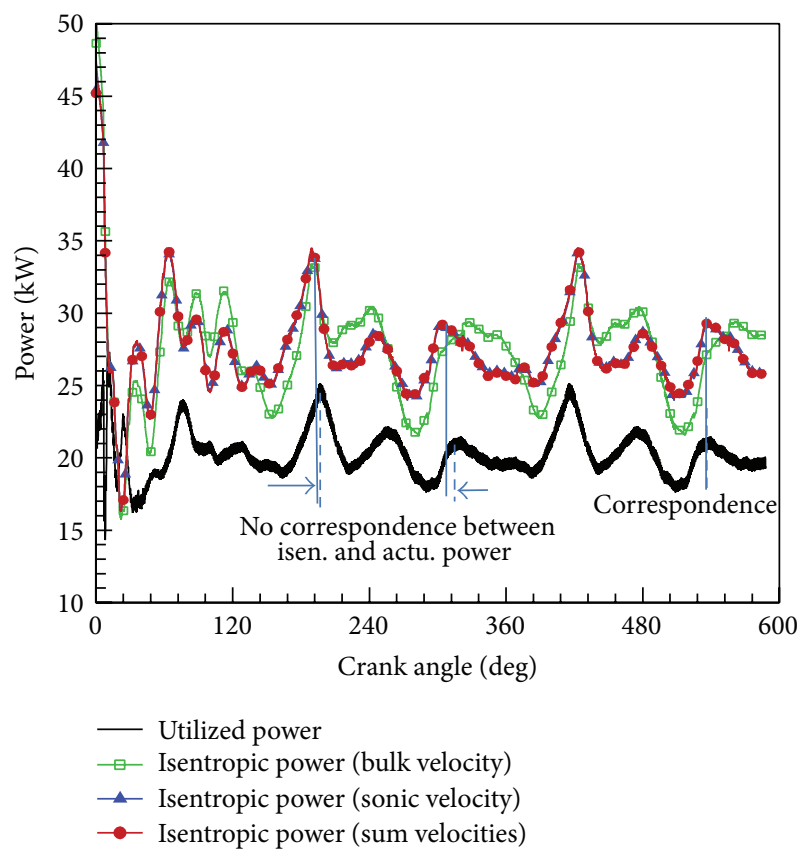

FIgURE 8: Simulated instantaneous isentropic and utilized power.

depending on the bulk flow velocity and the sonic velocity and the sum of them in order to evaluate the time lag. The mean time lag is found equal to $1.723 \mathrm{Tr}, 0.573 \mathrm{Tr}$, and $0.494 \mathrm{Tr}$ ( $\mathrm{Tr}$ represents the time necessary for the rotor to revolve one round), by taking the velocity of the pulse transport mechanism as the bulk flow velocity and the sonic velocity and the sum of them, respectively. An equivalent value of the time lag expressed in terms of crank angle attributed to previous values ( $16.57 \mathrm{deg}, 5.5058 \mathrm{deg}$, and $4.744 \mathrm{deg}$ ) depicts a high difference between the mean time lag calculated using the bulk flow velocity and that using the sonic velocity or the sum of them. Such difference could be related to the importance of the sonic velocity resulting from a high operating temperature. Figure 8 reveals that although taking into account the time shift in evaluating the isentropic inlet power, the maximum and the minimum of isentropic inlet power do not correspond to the maximum and minimum of the actual power. Thus, there is a nonconstant phase shift between isentropic and actual power which varies during the pulses. In practice, these time-dependent phase shifts may be explained by the fact of the inertial effect of the turbine rotor causing its rotation to continue even when the inlet pressure is low and this effect is not taken into account in the present simulations because Ansys-CFX only requires a constant rotational speed. In their LES, Hellstrom and Fuchs [14] captured this time-dependent behaviour and related it to the pulsatile inlet conditions, where the maximum phase shift occurs when the inlet flow changes its direction, and the minimum of phase shift occurs when the mass flow reaches its maximum. Given the uncertainty associated with the value of the time lag, an alternative issue is to evaluate the radial turbine performance by cycle averaging of the inlet and outlet parameters during one or more pulse cycles, thus avoiding the phase shifting.

To identify the effect of the apparent length in the evaluation of total-to-static efficiency, four apparent lengths were tested using the sum of bulk flow velocity and sonic velocity as the velocity of the pulses mechanism. Figure 9 shows that the effect of choosing the apparent length on the total-to-static efficiency is noticeable when using the approach based on the bulk flow velocity; however this effect is not clear for the other two approaches. The instantaneous shaft power and the total-to-static efficiency recorded at the beginning of simulations exhibit abrupt variations where the value of shaft power doubled and that of efficiency exceeded unity. However, the effect of pulses within the turbine implies a dynamic process; thus the instantaneous developed power is not a simple function of the current boundary condition but depends on the history of boundary conditions for some time prior to the moment of calculation [24]. Consequently, a lapse of time corresponding to $45 \mathrm{deg}$ of crank angle equivalent to a half of the complete period of pulse through the hub entry for these simulations is required to ensure that such a history is constituted and a periodic solution is reached.

4.3. Instantaneous Mass Flow Rate. For this twin-entry radial turbine, the instantaneous inlet and exit mass flow rates at each time step versus the crank angle are plotted as depicted in Figure 10. The instantaneous mass flow rate is derived by the summation of the discrete mass flows through a surface of the control volume over all integration points at inlet or outlet of the control volume. At the beginning of simulations, a strong variation of the inlet and outlet mass flow rates was recorded. A lapse of time corresponding to $45 \mathrm{deg}$ of crank angle (equivalent to a complete period of the pulses at hub entry) was required to ensure that a periodic solution is reached. The instantaneous mass flow rate behaviour for the two entries is more irregular than the pressure trace and mainly follows the features of the pressure signal. Furthermore, the inlet mass flow rate is in out-phase between the two entries following the imposed inlet total pressure features. Nevertheless, the mass flow rate at the outlet moves away from a sinusoidal feature as imposed at the outlet. During a fixed period from a position $\theta=45 \mathrm{deg}$ to $360 \mathrm{deg}$, the inlet mass flow rate fluctuates between $0.257 \mathrm{~kg} / \mathrm{s}$ and $0.344 \mathrm{~kg} / \mathrm{s}$, while the outlet mass flow rate fluctuates in a wider range from $0.19 \mathrm{~kg} / \mathrm{s}$ to $0.367 \mathrm{~kg} / \mathrm{s}$. The maximum outlet mass flow is higher than that at the inlet due to the emptyingfilling phenomena. However, the volume of the twin volute can be considered as a temporary tank in which the fluid can be accumulated and then discharged. Through the rise time of the pulse, the mass flow reaches a critical value related to the choked regime; after that the rotor is incapable of discharging the incoming fluid before the next pulse cycle resulting from both sides, thus causing an accumulation within the volute. Inversely, through the descent time of the pulse, the incoming mass flow drops hence allowing the rotor to consume the excessive fluid. However, the turbine has insufficient time to consume the gas mass within the working inlet pipe before the next pulse cycle, and storage of mass is taking place in the volute $[10,27]$. To quantify the instantaneous rate 


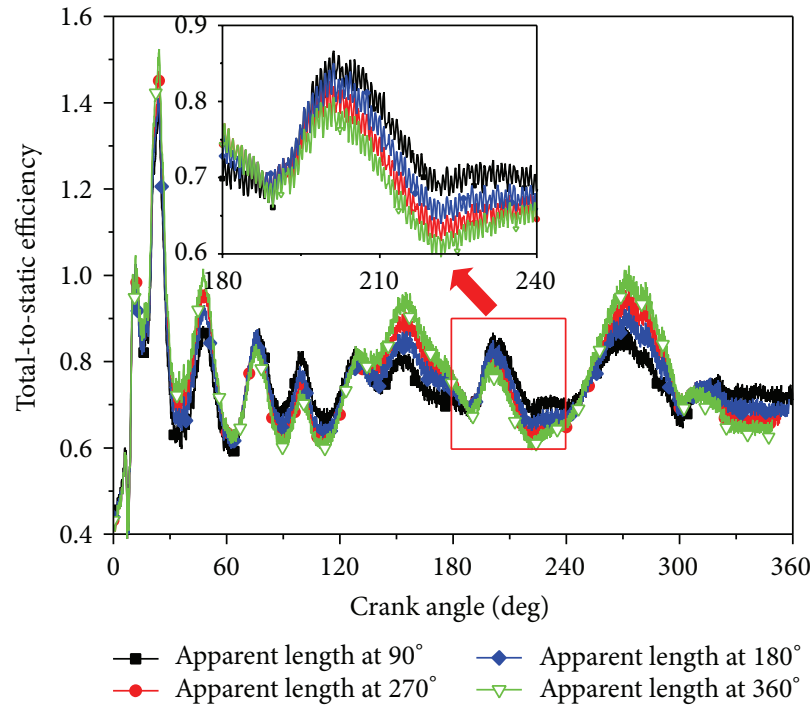

(a)

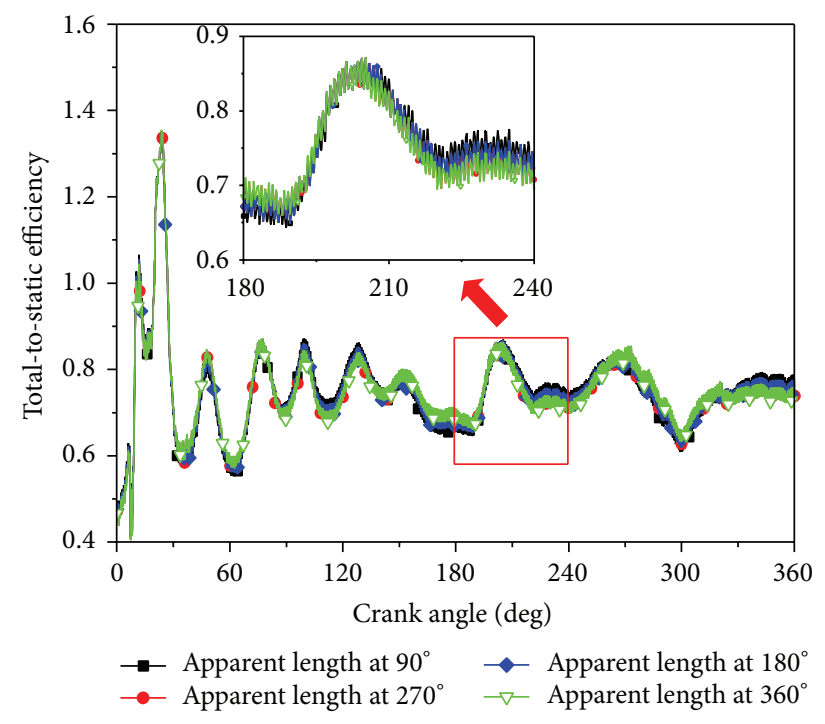

(b)

FiguRE 9: Total-to-static efficiency evaluated for different apparent length (a) bulk flow velocity and (b) sum of sonic velocity and bulk velocity, as velocity of pulse mechanisms.

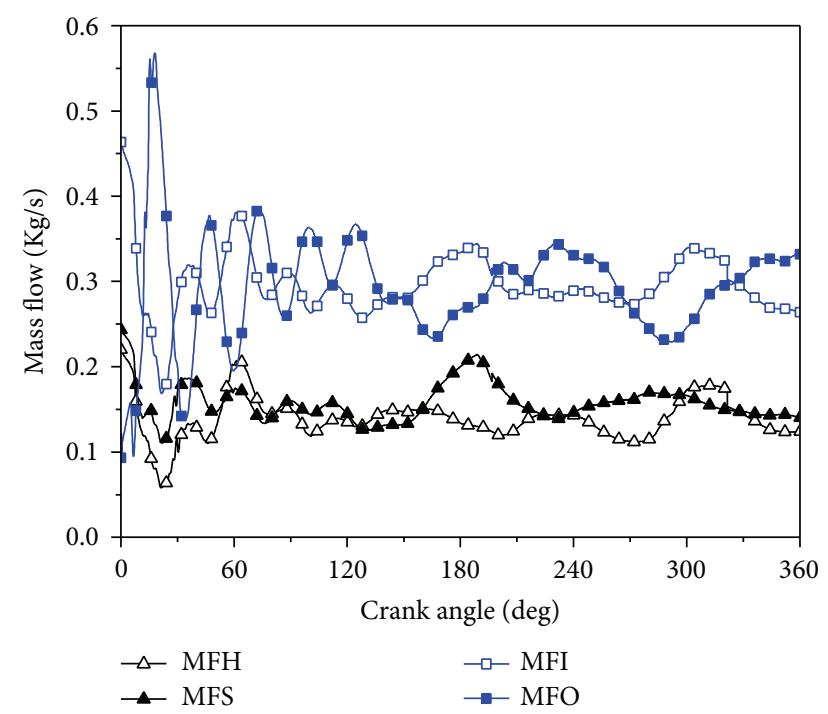

FIGURE 10: Instantaneous mass flow rate.

of this mass storage, Ehrlich [10] introduced the parameter $\left(\left(\dot{m}_{h}+\dot{m}_{s}-\dot{m}_{\text {out }}\right) /\left(\dot{m}_{h}+\dot{m}_{s}\right)\right)$ to describe the net rate of mass entering or leaving the twin-entry radial turbine as a percentage of the total mass flow entering the turbine at any instant. The surplus accumulated during the unequal admission and partial admission could be evacuated over other portions of the ICE cycle and therefore the conservation of mass flow is respected during a complete cycle. Figure 11 illustrates the evolution of mass storage parameter and reveals that, except at the beginning of the simulations, the mass storage and the discharge through this twin-entry radial turbine do not exceed the value of $30 \%$ of the total mass flow entering the turbine. Also, the storage mass parameter shows

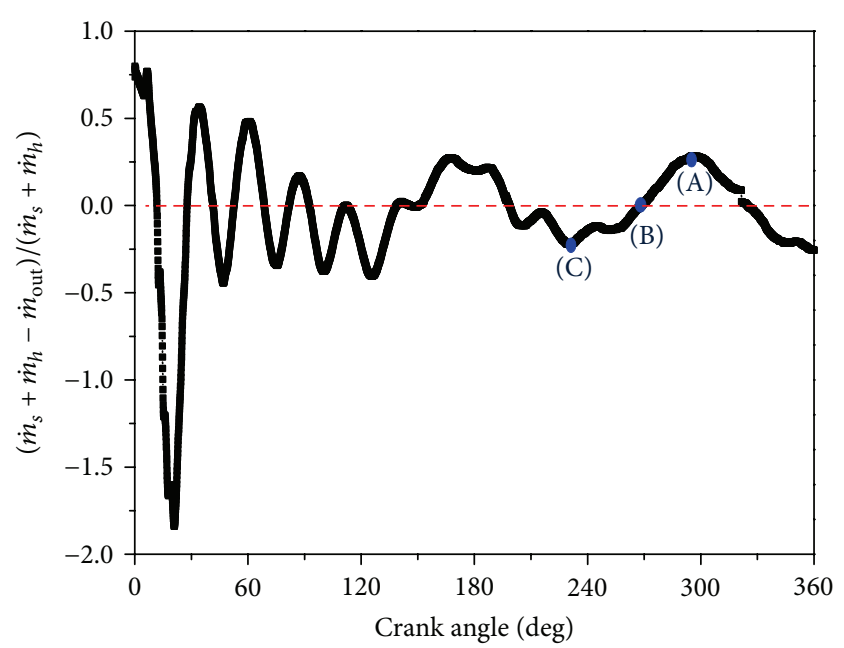

FIGURE 11: Mass storage parameter.

that the duration of the accumulation period represents approximately $70 \%$ of the discharge period wherein the rotor evacuates quickly the storage mass characterized by a high pressure and stored through the volume of volute.

Figure 12 depicts the distribution of static pressure at the mid-span of hub-side and shroud-side of the volute at three instants equivalent to maximum of mass flow rate accumulation (instant $\mathrm{A}$ ), maximum of mass flow discharge through the volute (instant $\mathrm{C}$ ), and no storage mass flow (instant B). At the instant of no storage mass flow (instant B), the static pressure distributions at mid-span of shroud-side and hub-side of the volute show that the volute distributes the flow in an axisymmetric way at the entry of rotor by transforming the potential energy of gases into kinetic energy 
Maximum accumulation

(A)
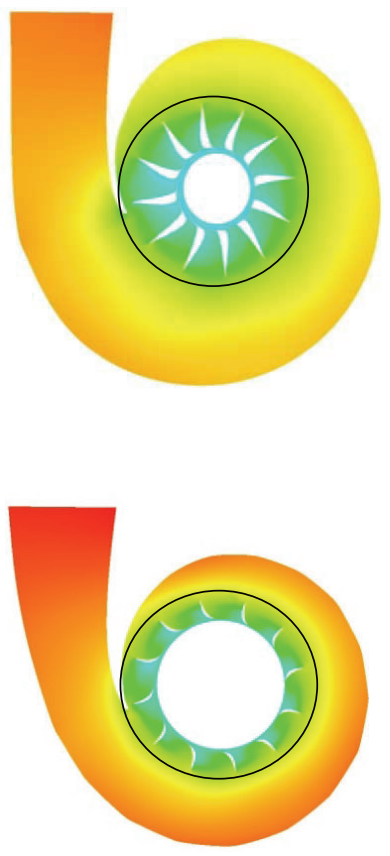

No mass storage

(B)

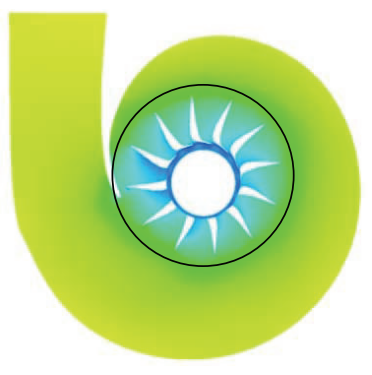

(a)

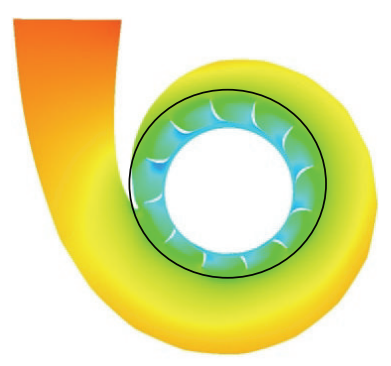

Maximum discharge

(C)

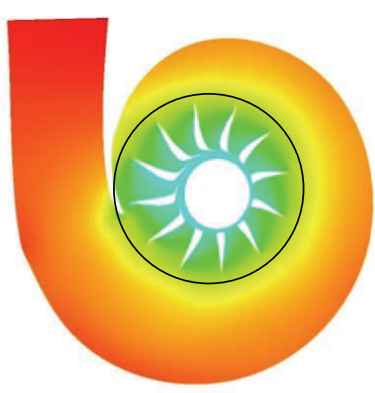

Pressure

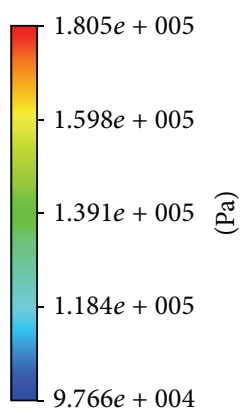

(b)

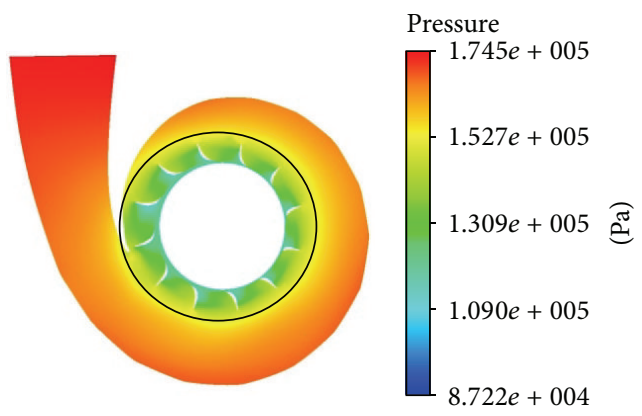

FIGURE 12: Static pressure distribution at mid-span, (a) hub-side of volute and (b) shroud-side of volute.

conformed to the free vortex design. A qualitative comparison of the flow field distributions between the shroudside and hub-side illustrates that the conversion of energy is much more evident in the shroud-side. At the instant of maximum of mass flow rate accumulation (instant $\mathrm{A}$ ), the flow field shows a gradual decrease of static pressure covering the forward and backward directions of interspaces area (beginning of the area of interspace shown by Figures 12 and 13 by a continued circle). On the other side, at the instant of maximum discharge (instant $\mathrm{C}$ ) a rapid drop in static pressure is shown within the interspace due to interactions between the two entries, where instantaneous unequal inlet admission is recorded at an angle of $268 \mathrm{deg}$. Nonuniformities observed near the tongue and a part of crossing flow that recovers the main flow are directly transmitted to the nearest blade. The ratio between this crossing flow and the instantaneous inlet mass flow at the instant of maximum storage (about $2.5 \%$ ) is less than the ratio at the maximum discharge (about 3\%).

In steady flow, the entropy rise and the total pressure loss coefficient both can be used to estimate the losses. However, due to the pulses through the radial turbine where both the total pressure and temperature highly fluctuate, subsequently the losses should be expressed in terms of entropy. Moreover, Denton [28] concluded that the most rational measure of loss generation in an adiabatic machine is in terms of entropy creation. By referring to the discussion in Sections 4.2 and 4.3 concerning (acoustic and convective and both) propagation of fluid properties, it can be seen that the choices of pulse transport mechanism are not obvious. Moreover, the effect of the pulses on the turbine performance in its rise time or descent time is not clear in terms of losses. As mentioned above, the pulse flow through the radial turbine is characterized by an accumulation and a discharge of the fluid within the volute. The following paragraph quantifies the losses caused by the emptying and the filling effect. The distributions of the static entropy at mid-span through the hub-side and the shroud-side of volute are shown in Figure 13. The generated static entropy intensifies backward of a position of $90 \mathrm{deg}$ from the tongue due to a subsequent separation as the flow is forced to return to feed the rotor, especially at the instant of no storage mass flow (instant B). However, the influence of the tongue region is clearly depicted forward to it at the instant of maximum discharge or maximum accumulation, as a consequence of the wake generated from the mixing between the inlet flow and that emerging from the tongue which circled around the rotor. The impact of the wake from the tongue seems to not extend any further than an azimuth angle of $90 \mathrm{deg}$. High entropy generated at the instant of maximum discharge (instant $\mathrm{C}$ ) is more concentrated at the hub-side than shroud-side, whereas a lower entropy is generated at the instant of maximum storage (instant A) at the hub-side than at the shroud-side.

4.4. Total-to-Static Efficiency versus RMF and Isentropic Velocity Ratio. Figures 14 and 15 plot the evolution of the total-to-static efficiency versus the reduced mass flow (RMF) parameter and the isentropic velocity ratio for the cases of steady and pulsatile flow conditions. As shown, this latter varies in a narrow range of the reduced mass flow parameter and is close to the optimum value of the isentropic velocity 
Maximum accumulation

(A)
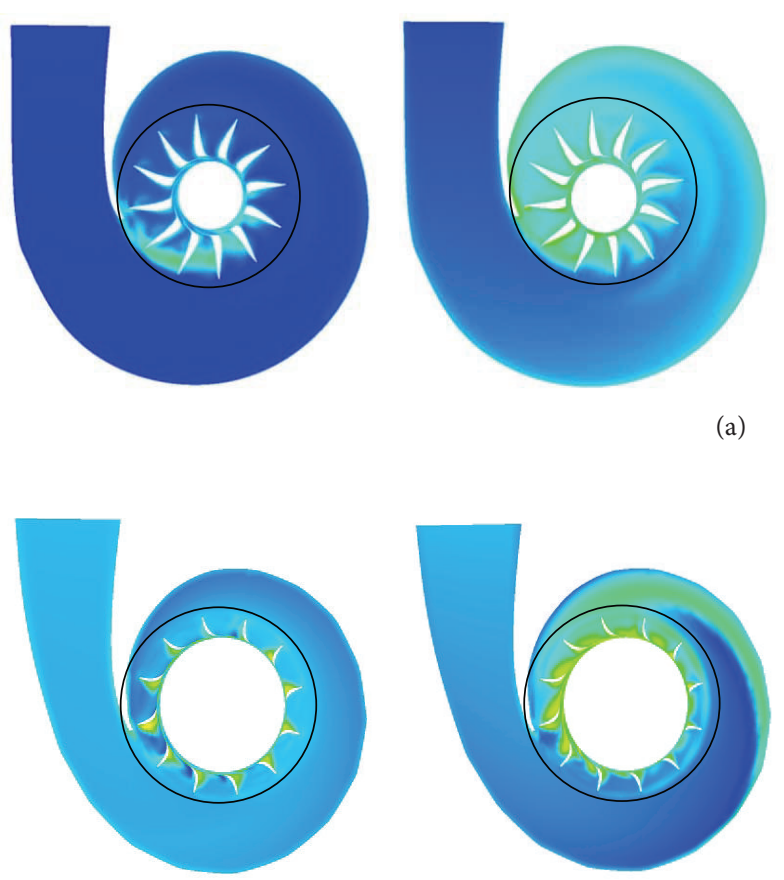

(a)

No mass storage

(B)

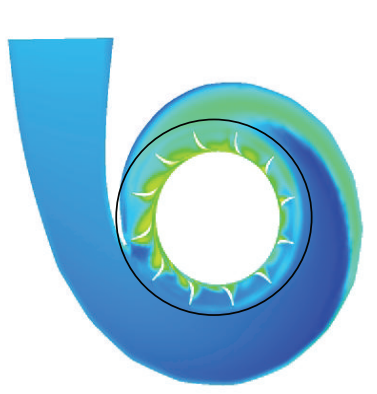

Maximum discharge

(C)
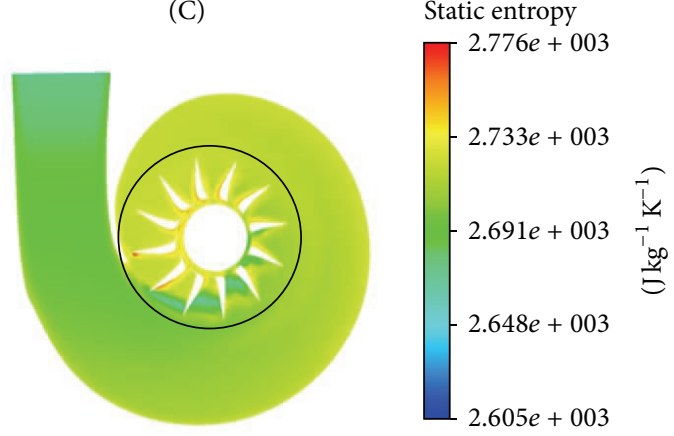

(b)

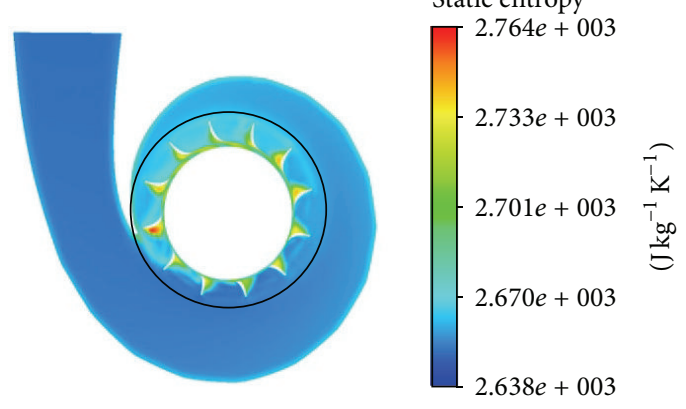

FIGURE 13: Static entropy distribution at mid-span, (a) hub-side of volute and (b) shroud-side of volute.

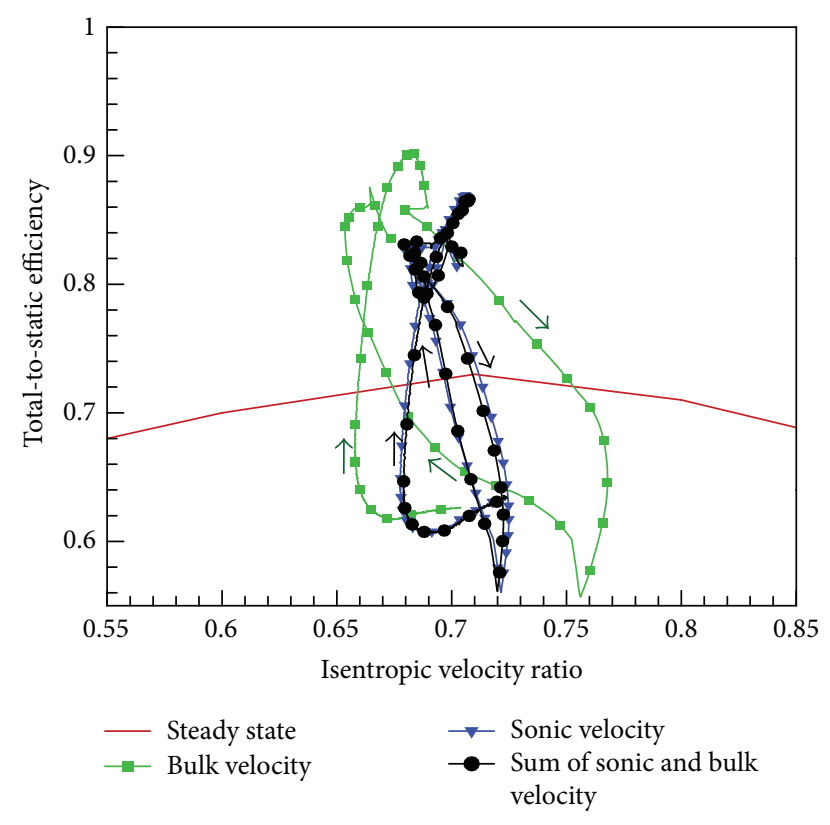

FIGURE 14: Total-to-static efficiency versus isentropic velocity ratio.

ratio. The unsteady performance is presented using the sum of the bulk flow velocity and the sonic velocity for evaluating the time lag between the isentropic condition and the actual condition. The asymmetric twin-entry radial

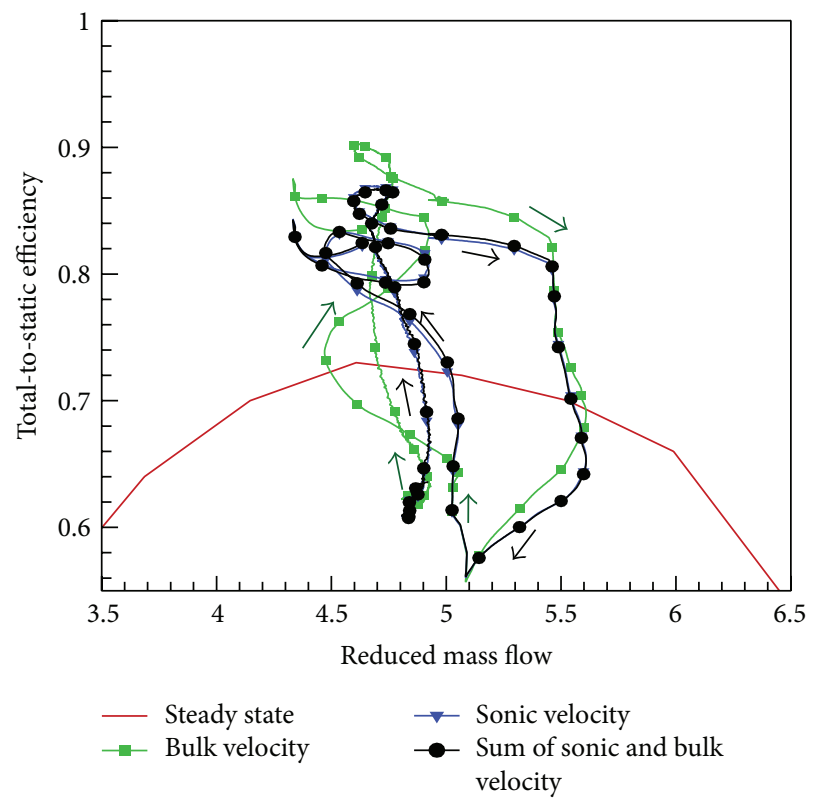

FIGURE 15: Total-to-static efficiency versus reduced mass flow parameter.

turbine with pulse flow at the two inlets indicates that the instantaneous performance and flow characteristics deviate substantially from their steady state values. This confirms that the quasi-steady assumption normally used in the assessment 


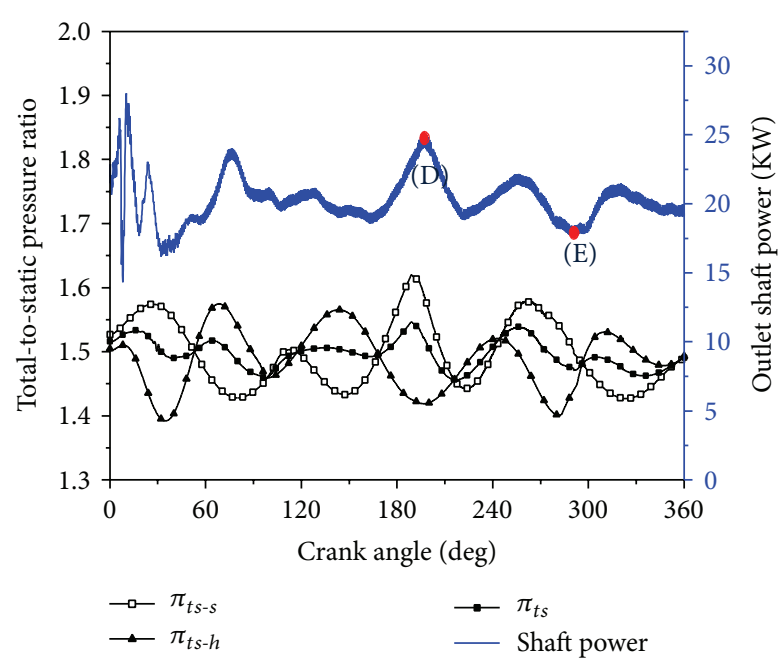

FIGURE 16: The instantaneous actual shaft power.

of performance is inadequate for the characterization of the efficiency in a pulsating environment of an automotive turbocharger. The results show that the efficiency versus isentropic velocity ratio departs from the steady state up to $+26 \%$ and $-22 \%$, whereas the efficiency versus reduced mass flow has $+25 \%$ and $-21 \%$ difference. For a twin-entry turbine, but with a symmetric volute, Dale and Watson [3] showed that the efficiency deviates with different unequal admission conditions, $+5 \%$ to $-12 \%$ from the steady equal admission line. This common looping curves behaviour as well depicted in the present numerical study was reported in the experiments of Arcoumanis et al. [26], Karamanis and Martinez-Botas [18], and Winterbone et al. [19] for a mixed flow turbine and Dale and Watson [3] and Ehrlich [10] for a twin-entry radial turbine. This looping behaviour is attributed to the continuous filling and emptying of the volute volume during the pulsating flow conditions; thus the imbalance between the inlet and outlet mass flow during the pulse occurs as explained by Chen et al. [29] and Karamanis and Martinez-Botas [18].

4.5. Unsteady Shaft Power and Total-to-Static Pressure Ratio. Figure 16 presents the behaviour of the shaft power and the total-to-static pressure ratio versus the crank angle. As seen, the shaft power is not constant when the inlet pressure through the hub-side entry and the shroud-side entry varies and tends to follow the trend of the mean total-to-static pressure ratio. The power shaft remains fairly flat for a minimum total-to-static pressure ratio related to the shroud-side entry, which is more sensitive to the inlet total pressure than the hub-side entry. Thus, through an increase of expansion ratio the efficiency rises and more mass flow passes through the turbine. The shaft power fluctuates with a frequency that corresponds to the blade passing frequency (BPF) of $12000 \mathrm{~Hz}$ (Figure 17) and modulated by a curve describing the inflow fluctuations. Similar behaviour has been reported in some papers studying radial turbines under pulsating flows, such as that of Palfreyman and Martinez-Botas [13], who

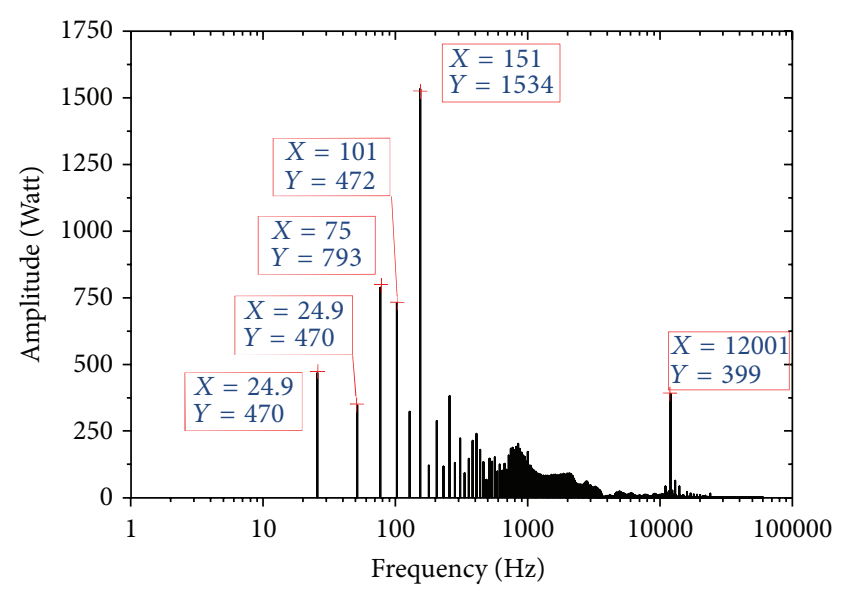

FIGURE 17: FFT spectrum of the actual shaft power signal.

conducted both computations and experiments to investigate the performance of a mixed flow turbine working under pulsatile flow conditions and showed that an oscillation with a frequency corresponding to the blade passage is superimposed on the shaft produced power. Recently Hellstrom and Fuchs [14-16], in their LES computations, highlighted this frequency. The resulting FFT analysis of the signal of the actual shaft power reveals the domination of the frequencies multiple of $25 \mathrm{~Hz}$, which may be related to the potential effect marked by the interaction between the incoming flow from the hub-side and the shroud-side at the interspace upward to the rotor. These interactions were highlighted in a previous work by Cerdoun and Ghenaiet [30] using the chorochronic periodicity developed by Tyler and Sofrin [31].

For identifying the effect of these interactions, Figure 18 plots the flow streamlines superimposed to the static entropy at a plane around the exit of volute located in the interspace at a distance of $4.2 \mathrm{~mm}$ from the divider, representing $70 \%$ of the distance between the divider and the volute exit. The plot is given for two instants, at the maximum of shaft power (D) and the minimum of shaft power (E). The flow in the interspace passing by the tongue depicts mixing near the divider and the streamlines follow a form of a bulge created between the main flow and the infiltrated flow owing to difference in velocities between the incoming flow through the tongue and the main flow. As a consequence, the flow structures in the interspace between shroud-side and hub-side are seen to be affected by the flow incidence at rotor entry, to provoke high losses (Figure 18). Therefore, the instant (D) associated with the maximum of shaft power is accompanied with low entropy generation in the shroud-side. On the other hand, the increase in entropy generation in the hub-side is marked by a decrease in the shaft power.

\section{Conclusion}

A twin-entry radial turbine operating under inlet pulsatile flows was studied considering more realistic inlet and outlet boundary conditions and the time lag. As a result, the instantaneous performance obtained at the design speed is 


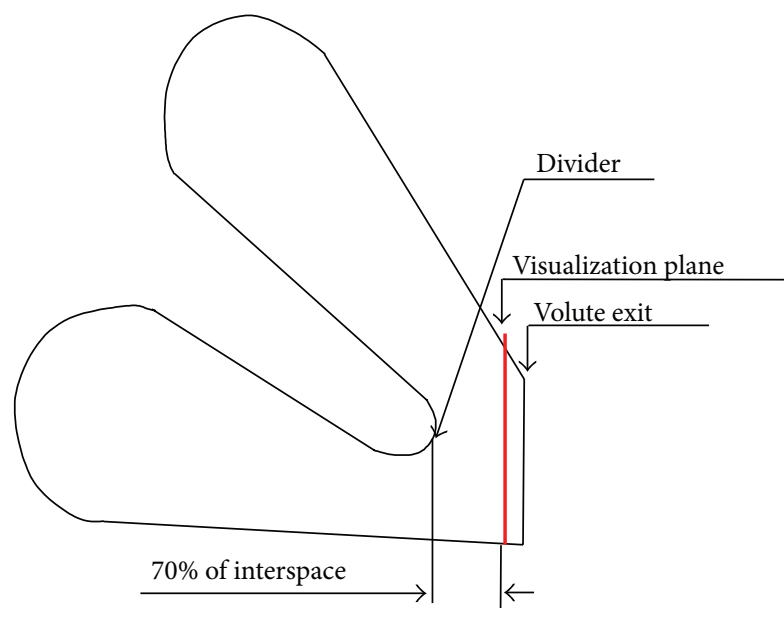

(a)

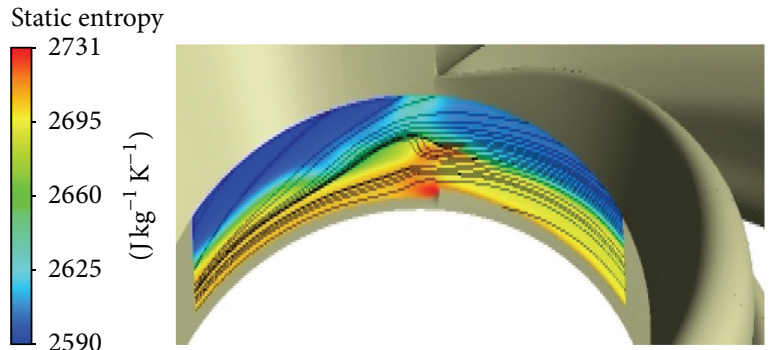

(b)

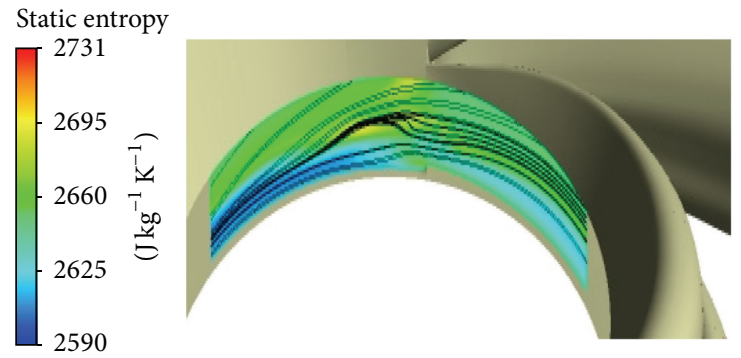

(c)

FIGURE 18: Streamlines over static entropy in the interspace at 70\% from the divider (detail (a)) and (b) instant of maximum shaft power and (c) instant of minimum shaft power.

shown to depart from that of steady state. The total pressure loss factor through the twin-entry volute is shown to behave in out-phase with the mean inlet total pressure, whereas the shaft power tends to follow the mean total-to-static pressure ratio. The choice of the time lag was of a considerable importance in evaluating the unsteady efficiency. The mass storage and discharge through this twin-entry radial turbine do not exceed $30 \%$ of the entering total mass. Also, the storage mass parameters show that the duration of accumulation period represents approximately $70 \%$ of discharge period. The entropy generation is seen to be more marked at the period of discharge whereas the minimum occurs during the period of mass flow storage. The shaft power fluctuates with a frequency corresponding to BPF and according to the entropy generated through hub-side and shroud-side of volute. Moreover, there is a nonconstant phase shift between the isentropic and the actual power which varies with the pulses. It appears that the parameters affecting the phase shift not only could be limited to the velocity of pulse transport mechanism, but also may be extended to the pulse frequency, amplitude, and temporal local gradient of mass flow and pressure wave.

\section{Notations}

$P_{t}:$ Total pressure $[\mathrm{Pa}]$

$T_{t}$ : Total temperature $[\mathrm{K}]$

$$
\begin{array}{ll}
p: & \text { Static pressure }[\mathrm{Pa}] \\
\dot{m}: & \text { Mass flow }\left[\mathrm{kg} \cdot \mathrm{s}^{-1}\right] \\
P: & \text { Power }[\text { Watt }] \\
T_{\text {Shaft }}: & \text { Shaft torque }[\mathrm{N} \cdot \mathrm{m}] \\
f: & \text { Force }[\mathrm{N}] \\
r: & \text { Radius }[\mathrm{m}] \\
t: & \text { Time }[\mathrm{s}] .
\end{array}
$$

\section{Greek}

$\omega:$ Rotational speed $\left[\mathrm{rad} \cdot \mathrm{s}^{-1}\right]$

$\theta$ : Circumferential coordinate [deg].

\section{Subscripts}
$h$ : Hub
$s: \quad$ Shroud
out: Outlet.

\section{Abbreviations}

BPF: Blade passing frequency

CFD: Computational fluid dynamic

MFR: Mass flow ratio

LES: Large eddy simulations

RMF: Reduced mass flow 
SMM: Sliding mesh model

URANS: Unsteady Reynolds Average Navier-Stokes.

\section{Competing Interests}

The authors declare no competing interests.

\section{References}

[1] A. Romagnoli, C. D. Copeland, R. F. Martinez-Botas, S. Martin, S. Rajoo, and A. Costall, "Comparison between the steady performance of double-entry and twin-entry turbocharger turbines," Journal of Turbomachinery, vol. 135, no. 1, Article ID 011042, 11 pages, 2012.

[2] F. Pischinger and A. Wunsche, "The characteristic behaviour of radial turbines and its influence on the turbocharging process," in Proceedings of the CIMAC Conference, pp. 545-568, Tokyo, Japan, 1977.

[3] A. Dale and N. Watson, "Vaneless radial turbocharger turbine performance," in Proceedings of the IMechE, C110/86, pp. 65-76, 1986.

[4] M. Capobianco and A. Gambarotta, "Performance of a twinentry automotive turbocharger turbine," ASME Paper 93-ICE2, 1993.

[5] A. Romagnoli, R. F. Martinez-Botas, and S. Rajoo, "Steady state performance evaluation of variable geometry twin-entry turbine," International Journal of Heat and Fluid Flow, vol. 32, no. 2, pp. 477-489, 2011.

[6] S. Rajoo, A. Romagnoli, and R. F. Martinez-Botas, "Unsteady performance analysis of a twin-entry variable geometry turbocharger turbine," Energy, vol. 38, no. 1, pp. 176-189, 2012.

[7] A. Hajilouy, M. Rad, and M. R. Shahhosseini, "Modelling of twin-entry radial turbine performance characteristics based on experimental investigation under full and partial admission conditions," Scientia Iranica, vol. 16, no. 4, pp. 281-290, 2009.

[8] J. R. Serrano, F. J. Arnau, V. Dolz, A. Tiseira, and C. Cervello, "A model of turbocharger radial turbines appropriate to be used in zero- and one-dimensional gas dynamics codes for internal combustion engines modelling," Energy Conversion and Management, vol. 49, no. 12, pp. 3729-3745, 2008.

[9] M. Iwasaki, N. Ikeya, Y. Marutani, and T. Kitazawa, "Comparison of turbocharger performance between steady flow and pulsating flow on engines," SAE Paper 940839, 1994.

[10] D. A. Ehrlich, Characterisation of unsteady on-engine turbocharger turbine performance [Ph.D. thesis], Purdue University, 1998.

[11] S. Rajoo and R. F. Martinez-Botas, "Unsteady effect in a nozzled turbocharger turbine," Journal of Turbomachinery, vol. 132, no. 3, Article ID 031001, 2010.

[12] J. K. W. Lam, Q. D. H. Roberts, and G. T. McDonnell, "Flow modelling of a turbocharger turbine under pulsating flow," in Proceedings of the ImechE Conference Transactions from 7th International Conference on Turbochargers and Turbocharging, pp. 181-196, London UK, May 2002.

[13] D. Palfreyman and R. F. Martinez-Botas, "The pulsating flow field in a mixed flow turbocharger turbine: an experimental and computational study," Journal of Turbomachinery, vol. 127, no. 1, pp. 144-155, 2005.

[14] F. Hellstrom and L. Fuchs, "Numerical computations of pulsatile flow in a turbo-charger," in Proceedings of the 46th AIAA
Aerospace Sciences Meeting and Exhibit, Aerospace Sciences Meetings, AIAA 2008-735, 2008.

[15] F. Hellstrom and L. Fuchs, "Effects of inlet conditions on the turbine performance of a radial turbine," ASME Paper GT200851088, 2008.

[16] F. Hellstrom and L. Fuchs, "Numerical computation of the pulsatile flow in a turbocharger with realistic inflow conditions from an exhaust manifold," ASME Paper GT2009-59619, 2009.

[17] M. H. Padzillah, S. Rajoo, and R. F. Martinez-Botas, "Numerical assessment of unsteady flow effects on a nozzled turbocharger turbine," in Proceedings of the ASME Turbo Expo: Turbine Technical Conference and Exposition, Paper no. GT2012-69062, pp. 745-756, Copenhagen, Denmark, June 2012.

[18] N. Karamanis, R. F. Martinez-Botas, and C. C. Su, "Mixed flow turbines: inlet and exit flow under steady and pulsating conditions," Journal of Turbomachinery, vol. 123, no. 2, pp. 359$371,2001$.

[19] D. E. Winterbone, B. Nikpour, and G. I. Alexander, "Measurements of the performance of a radial inflow turbine in conditional steady and unsteady flow," in Proceedings of the ImechE Conference Transactions, 4th International Conference: Turbocharging and Turbochargers, C405/015, pp. 153-160, 1990.

[20] S. Szymko, R. F. Martinez-Botas, and K. R. Pullen, "Experimental evaluation of turbocharger turbine performance under pulsating flow conditions," ASME Paper GT2005-68878, 2005.

[21] J. K. W. Lam, Q. D. H. Roberts, and G. T. Mcdonnell, "Flow modelling of a turbocharger turbine under pulsating flow," in Turbocharging and Turbochargers, I Mech E, pp. 181-197, 2002.

[22] N. C. Baines, Turbocharger Turbine Pulse Flow Performance and Modelling-25 Years On, Concepts NREC, Hartford, Vt, USA, 2010.

[23] S. Rajoo and R. Martinez-Botas, "Mixed flow turbine research: a review," Journal of Turbomachinery, vol. 130, no. 4, Article ID 044001, 2008.

[24] A. Ghenaiet, "Predicting the aerodynamic performance of turbocharger components," IMechE Compressors and Their Systems Paper C658/010/07, Chandos, Oxford, UK, 2007.

[25] N. A. Cumpsty and J. H. Horlock, "Averaging nonuniform flow for a purpose," Journal of Turbomachinery, vol. 128, no. 1, pp. 120-129, 2006.

[26] C. Arcoumanis, I. Hakeem, L. Khezzar, and R. F. MartinezBotas, "Performance of a mixed flow turbocharger turbine under pulsating flow conditions," ASME Paper 95-GT-210, 1995.

[27] S. Marelli and M. Capobianco, "Measurement of instantaneous fluid dynamic parameters in automotive turbocharging circuit," in Proceedings of the 9th SAE International Conference on Engines and Vehicles, 2009-24-0124, 2009.

[28] J. D. Denton, “The 1993 IGTI scholar lecture: loss mechanisms in turbomachines," Journal of Turbomachinery, vol. 115, no. 4, pp. 621-656, 1993.

[29] H. Chen, I. Hakeem, and R. F. Martinez-Botas, "Modelling of a turbocharger turbine under pulsating inlet conditions," Proceedings of IMechE, Part A: Journal of Power and Energy, vol. 210, pp. 397-408, 1996.

[30] M. Cerdoun and A. Ghenaiet, "Analyses of steady and unsteady flows in a turbocharger's radial turbine," Proceedings of IMechE, Part E: Proc IMechE Part E: Journal of Process Mechanical Engineering, vol. 229, no. 2, pp. 130-145, 2015.

[31] J. M. Tyler and T. G. Sofrin, "Axial flow compressor noise studies," SAE Transaction, vol. 70, pp. 309-332, 1962. 


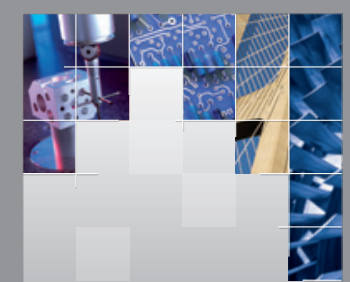

\section{Enfincering}
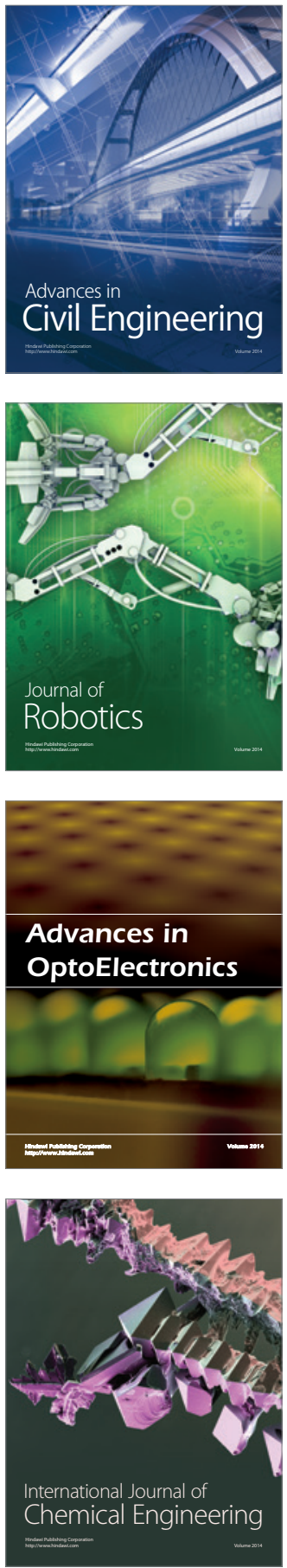

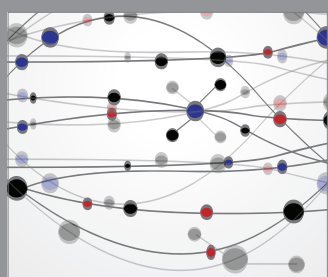

The Scientific World Journal

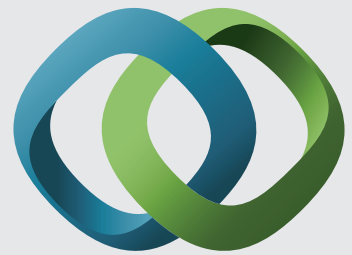

\section{Hindawi}

Submit your manuscripts at

http://www.hindawi.com
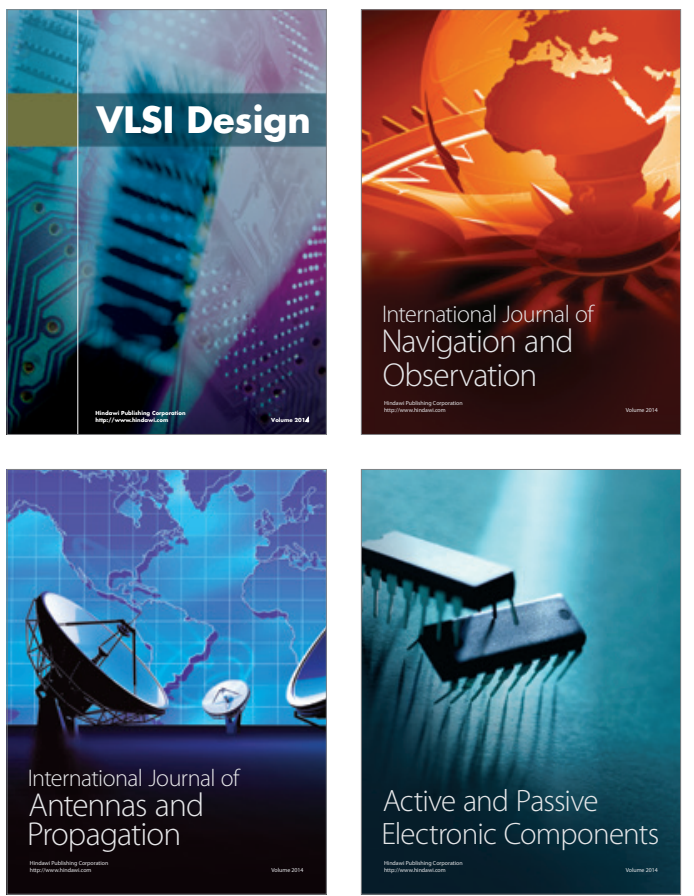
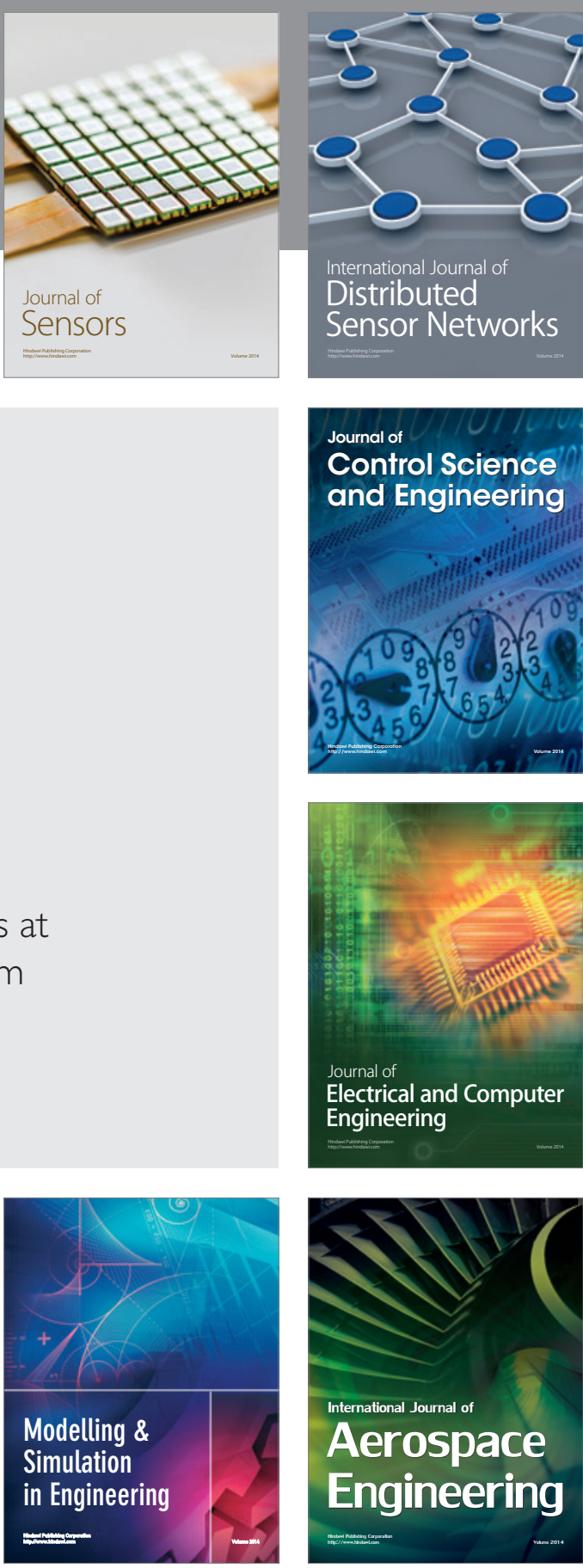

International Journal of

Distributed

Sensor Networks

Journal of

Control Science

and Engineering
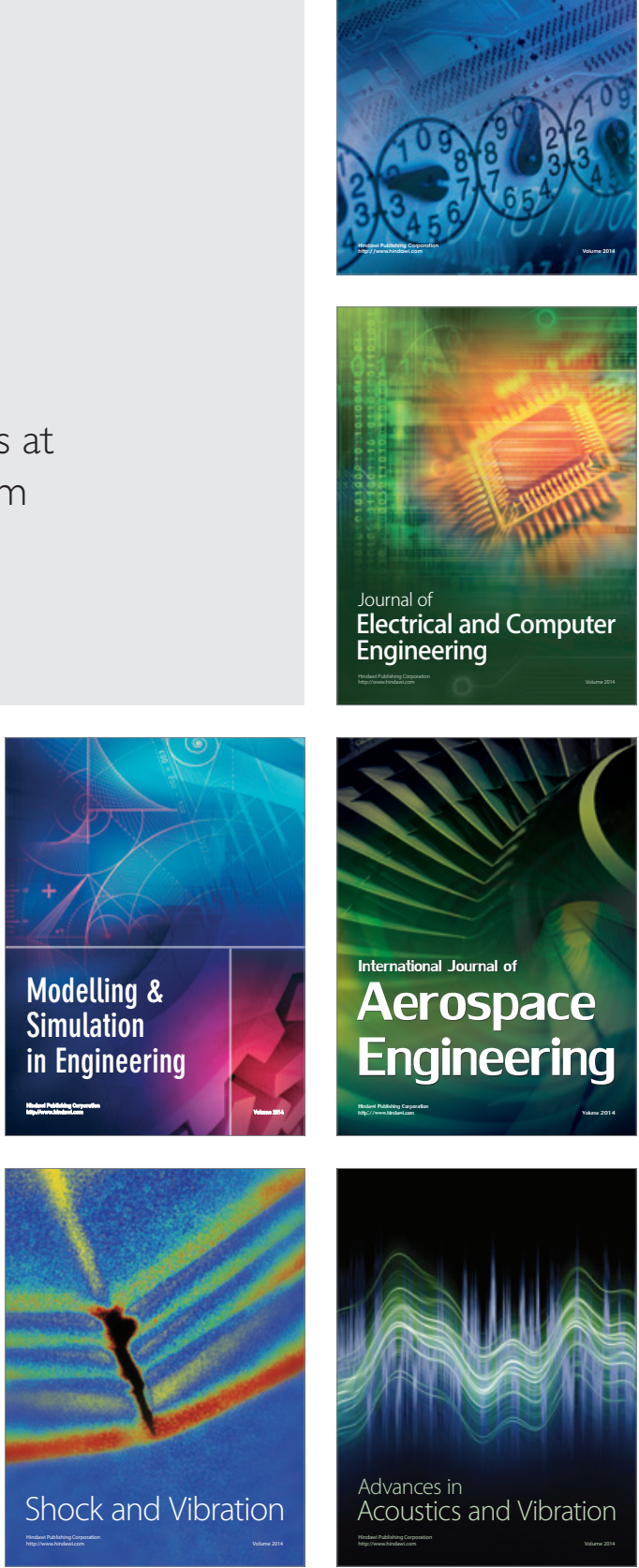